\title{
ATM Knockdown renders Glioma resistant to Temozolomide by Inhibiting IFIT1 Expression
}

Lijuan Yang ( $\square$ lijuanyang8899@163.com )

Fujian Medical University

Jinfeng Zhang

Sanbo Funeng Brain Hospital

\section{Shengmei Weng}

Fujian Medical University

\section{Zhixiong Lin}

Capital Medical University Sanbo Brain Hospital

\section{Research}

Keywords: TMZ, Malignant glioma, Chemoresistance, MGMT, ATM, IFIT1

Posted Date: March 18th, 2021

DOI: https://doi.org/10.21203/rs.3.rs-304467/v1

License: (c) (7) This work is licensed under a Creative Commons Attribution 4.0 International License. Read Full License 


\section{Abstract}

Background: Temozolomide (TMZ) chemotherapy has been a standard of care in treating malignant glioma. Although $T M Z$ chemotherapy can extend patient's survival, resistance to TMZ is observed in most cases. The drug resistance is reported to be mainly mediated by 06- methyl guanine-DNA methyltransferase (MGMT) expression.

Methods: By means of molecular biology, cell biology, construction of nude mouse xenograft tumor model and analysis of clinical specimens, a new molecular mechanism for the regulation of TMZ chemotherapy resistance of glioma was proposed.

Result: The present study indicates a pathway of TMZ resistance in glioma via suppressing ataxia-telangiectasia mutated (ATM) gene. Whole genome expression profile of glioma cells and tissue samples revealed a positive correlation between the ATM and IF1T1, the decreased expression of which might be the underlying cause of the ATM knockdown induced $\mathrm{TMZ}$ resistance.

Conclusions: Our study revealed that ATM silencing induced TMZ chemotherapy resistance of glioma in vitro and in vivo by inhibite IFIT1 expression, the p-ATM, IFIT1 and MGMT expression acts as a prognostic marker of glioma chemotherapy. And combination of IFIT1 and MGMT seems to be a more significant molecular marker to predict the prognosis in glioma patients.

\section{Introduction}

Malignant glioma is a progressive brain tumor with high morbidity and mortality. In recent times, a multidisciplinary approach of treating gliomas using surgery and radiotherapy coupled with chemotherapy, predominantly with temozolomide (TMZ) [1, 2], has been a used to improve the survival and quality of life. Although TMZ chemotherapy can extend patient's survival, resistance to TMZ is observed in most cases, which leads to poor prognosis of glioma [3, 4]. The drug resistance is reported to be mainly mediated by 06- methyl guanine DNA methyltransferase (MGMT), generated by TMZ [5]. The activation of MGMT depends on the occurrence of DNA damage response (DDR), where mutation of ataxia-telangiectasia mutated (ATM) gene is the key regulator of the process [6]. The double-stranded DNA damage caused by cell cycle arrest, apoptosis and DNA damage repair play an important role in signal transduction pathways $[7,8]$. ATM is a mutant gene in ataxia-telangiectasia (AT), located on human chromosome 11q22 23 [9] with a total length of about $150 \mathrm{~kb}$, encoding sequence of about $12 \mathrm{~kb}$ [10], and is involved in regulating cell cycle, repairing damaged DNA and maintaining telomere length. ATM is found to promote cell proliferation through protein kinase B (PKB/Akt) pathway $[11,12]$.

Understanding several mechanism of TMZ resistance and strategies to overcome it to enhance the effect of TMZ for a successful treatment efficacy of glioma is of utmost importance. Thus, in view of this hypothesis, the present study aims to explore the molecular mechanism of glioma TMZ chemotherapy resistance induced by ATM silencing. This was carried out using human genome-wide screening, chips and HCS system on glioma U251 cells. We found that ATM knockdown increase the resistance of TMZ, by inhibiting the expression of IFIT1. ATM promote cell apoptosis by inducing the expression of IFIT1, improve the sensitivity of glioma TMZ chemotherapy, and improve the clinical prognosis of glioma patients.

\section{Materials And Methods}

Glioma tissues, Cell culture and stable cell line construction. This study protocol was reviewed and approved by the hospital ethics committee, Sanbo Brain Hospital of Capital Medical University. Post consent, 70 glioblastoma tissues, from the patients who underwent surgical resection of glioblastoma, were obtained from the department of clinical 
surgery. Each sample was cut into half, with one half stored in $4 \%$ paraformaldehyde and the other half was frozen in liquid nitrogen and stored at $-80^{\circ} \mathrm{C}$ till further use. U251, U87, LN229, U373 and 293T cell lines were purchased from Shanghai cell institute. HEB, HepG2, Hela, and MCF-7 cell lines were maintained in our laboratory. All cells were cultured in RPMI 1640 or DMEM, supplemented with $10 \%$ FBS, $100 \mathrm{U} / \mathrm{mL}$ penicillin, and $100 \mathrm{mg} / \mathrm{mL}$ streptomycin, and incubated at $37{ }^{\circ} \mathrm{C}$ under $5 \% \mathrm{CO}_{2}$. Further, we constructed U251 and U87 stable ATM knockdown cell lines, through lentivirus (LVsiATM-KD1 and LV-siATM-KD2) infection; the cells are hereby referred to as siATM-KD1 and siATM-KD2, respectively, with control cells referred to as ATM-NC.

qRT-PCR. Total RNA from glioma cells and tissues were extracted by TRIzol reagent kit (TaKaRa, Japan), eluted by RNase free $d d \mathrm{H}_{2} \mathrm{O}$ and stored at $-80^{\circ} \mathrm{C}$. The reverse transcription was then performed with TAKARA retrovirus kit (TAKARA, Japan) as follows: $37^{\circ} \mathrm{C}$ for $1 \mathrm{~h}$ and $85^{\circ} \mathrm{C}$ for $15 \mathrm{~s}$. SYBR-green PCR Master Mix (TaKaRa, Japan) and primers (Table 1) were used for qRT-PCR, carried on bio-rad iQ5 system (bio-rad, USA), ATM or IFIT1 expression was quantified using the $2^{-\Delta \Delta C q}$ method[13].

Table 1

Proliferation of U87 and U251 cells after ATM knockdown on 5th of TMZ (IC50) chemotherapy

\begin{tabular}{|lllll|}
\hline Groups & $\begin{array}{l}\text { proliferation } \\
\text { rate }\end{array}$ & $\boldsymbol{P}$ & $\begin{array}{l}\text { Chemotherapy proliferation } \\
\text { rate }\end{array}$ & $\begin{array}{l}\text { Chemotherapy inhibition } \\
\text { rate(\%) }\end{array}$ \\
\hline U87NC & $4.03 \pm 0.14$ & & & \\
\hline U87siATM-1 & $4.10 \pm 0.08$ & 0.688 & & $27.5 \pm 3.8$ \\
\hline U87NC+ TMZ & $2.92 \pm 0.16$ & & $0.73 \pm 0.04$ & $21.0 \pm 1.7$ \\
\hline $\begin{array}{l}\text { U87siATM-1 + } \\
\text { TMZ }\end{array}$ & $3.24 \pm 0.07$ & & $0.79 \pm 0.02$ & \\
\hline U251NC & $2.45 \pm 0.29$ & & & \\
\hline U251siATM-1 & $2.56 \pm 0.20$ & 0.525 & & $36.8 \pm 2.0$ \\
\hline U251NC+ TMZ & $1.55 \pm 0.05$ & & $0.63 \pm 0.02$ & $29.1 \pm 3.0$ \\
\hline $\begin{array}{l}\text { U251siATM-1 }+ \\
\text { TMZ }\end{array}$ & $1.81 \pm 0.07$ & & $0.71 \pm 0.03$ & \\
\hline
\end{tabular}

Western blot analysis. Glioma cells were lysed using RIPA lysis buffer (Thermo Fisher Scientific, USA) and centrifuged at $4{ }^{\circ} \mathrm{C}$ after ultrasonic processing. Sample buffer, containing $20 \%$ of SDS, was then added and boiled for 6 minutes until complete denaturation of protein occurred, which was then stored at $-20^{\circ} \mathrm{C}$ until further used. During experimentation, all protein was separated by SDS-PAGE, transferred onto PVDF membrane and incubated with block buffer for $2 \mathrm{~h}$ at room temperature. The samples were then incubated with ATM antibody (1:2000, Abcom, ab199726), IFIT1antibody (1:200, Abcom, ab236256) or GAPDH antibody (1:10000, Abcom, ab181602), at $4{ }^{\circ} \mathrm{C}$ overnight. The membrane was then washed 3 times with TBST buffer and incubated with goat anti-rabbit lgG H\&L (HRP) secondary antibody (1:5000, Abcom, ab6721) for $2 \mathrm{~h}$ at room temperature. Protein expression was then assessed by chemiluminescence method.

MTT assay. Cell viability in response to TMZ chemotherapy was examined using MTT assay (CCK8, Sangon Biotech, Shanghai, China). U251 and U87 cells were plated onto 96-well plates at $2 \times 10^{3}$ cells per well. Next day, the cells received $50,100,200,400$ or $800 \mu$ mols of TMZ, and incubated for $96 \mathrm{~h}$. Later, $10 \mu \mathrm{l}$ of $5 \mathrm{mg} / \mathrm{ml}$ MTT regent was added to each well containing $100 \mu \mathrm{l}$ medium, and incubated at $37^{\circ} \mathrm{C}$, under $5 \% \mathrm{CO}_{2}$, for $4 \mathrm{~h}$. The reaction was then terminated by replacing the medium with $100 \mu \mathrm{DMSO}$, and the plates were read at $490 \mathrm{~nm}$ using a microplate reader. 
Clonogenic assay. U251 and U87 cells were seeded in 6-well plates, at a density of $1 \times 10^{2}$ cells/well, and cultured in DMEM medium containing 10\% FBS for 10-14 days. The cells were then fixed with $4 \%$ paraformaldehyde for 15 min, and stained with $0.1 \%$ crystal violet. Visible colonies and the number of clones in each group were counted under a light microscope. The experiment was repeated three times.

Immunohistochemical staining. The 4\% paraformaldehyde fixed and paraffin embed pathological specimens of the included patients, were subject to heat mediated antigen retrieval, under EDTA (pH 9.0; for MGMT) or Citrate buffer (pH 6.0; for all other antigens). The slides were then rinsed once with PBS and thrice with TBST, 2 minutes each, and incubated with $100 \mu \mathrm{l}$ of $3 \% \mathrm{H}_{2} \mathrm{O}_{2}$ for $10 \mathrm{~min}$ at room temperature. Post rinse with TBST, the slides were incubated with P - ATM (1:100, phospho - Ser1981 TA309979, OriGene Technologies, Inc. USA); IFIT1 (1:100, GTX84315, GeneTex, Inc. USA); MGMT (1:100, ab39253, Abcam, UK); Ki - 67 (1:100, clone MIB1, M7240, DakoCytomation, Denmark) for $1 \mathrm{~h}$ at room temperature. Following manufacturer's instructions, the rinsed slides were then incubated at room temperature with 2 drops (about $100 \mu \mathrm{l}$ ) of PV9000 reagent 1 for 20 min, followed by 2 drops (about $100 \mu l$ ) of PV9000 reagent 2 for $30 \mathrm{~min}$. The slides were then washed with TBST 3 times, 2 min each, and were treated with 2 drops (about $100 \mu l)$ of DAB for color development. Post wash under running water for $10 \mathrm{~min}$, the slides were subject to Hematoxylin stain before sealing with neutral gum and observed under a light microscope.

Subcutaneous tumor transplantation assay. Nude mice ( 6 to 8 weeks old) were obtained from animal experiment center of Fujian medical university, Fujian, China. U87-NC and U87-siATM-1 cells in logarithmic growth phase were subcultured for two days before inoculation, to ensure optimal cell viability. Five million cells were subcutaneously injected into the flanks of each mouse to generate the subcutaneous tumors. Tumor formation was observed at 5 days after implantation. The body weight of the mice and tumor volume (along the long diameter $(\mathrm{L})$ and short diameter $(\mathrm{W})$ of tumor blocks) were recorded at this time. The approximate volume of tumor was calculated according to the formula: tumor volume $=\pi / 6 \times \mathrm{L} \times \mathrm{W} \times \mathrm{W}$. When more than half of the nude mice in the U87-NC group had tumor volume greater than $0.5 \mathrm{~cm}^{3}$, TMZ chemotherapy was started at a dose of $60 \mathrm{mg} / \mathrm{kg} / \mathrm{d}$ orally, with No. 6 gavage needle, for five consecutive days. The dose and medication days of $\mathrm{TMZ}$ were adjusted according to the weight and state of nude mice, and dead mice were not included in the study assessments. Considering the status of tumor growth, the nude mice were euthanized between 2-3 weeks of TMZ administration, by cervical dislocation. The tumors, collected from each mouse, were macroscopically evaluated, photographed and weighed before cutting into two halves. One half of the tumor was fixed with paraformaldehyde and stored at room temperature, while the other half was frozen with liquid nitrogen, and stored at $-80^{\circ} \mathrm{C}$, for later use. Animal experiments in the present study had been approved by the Ethics Committee of Sanbo Brain Hospital Institutional Review Board and their care was in accordance with institution guidelines.

Statistical analysis. All the statistical analysis was performed using SPSS 19.0 software (SPSS Inc, Chicago, IL, USA. Data are expressed as mean \pm standard deviation. Student $T$ test was used to analyze the difference between two groups, while ANOVA test was conducted for multiple comparable groups. The overall survival curve was estimated using the Kaplan-Meier method, and the difference in survival was evaluated using the log-rank test. $P<0.05$ was considered to indicate a statistically significant difference.

\section{Result}

High expression of ATM in human glioma cell lines and tissues. Expression of ATM was determined in HEB, the human normal glial cell line, and U87, U251, LN229 and U373, the human glioma cell lines, by qRT-PCR (Fig. 1A) and western blot (Fig. 1B). All glioma cell lines expressed significantly higher levels of ATM as compared to HEB $(P<0.001)$ (Fig. 1A\&B). Further, the expression of ATM in glioma tissue and its adjacent normal tissue was also detected by qRTPCR and western blot. Following the trend, the mRNA level of ATM was found significantly increased in glioma tissue as compared to its adjacent tissue $(P<0.001)$ (Fig. 1C\&D). 
ATM silencing induced TMZ chemotherapy resistance of glioma in vitro. U251-LV-ATM-KD and U87-LV-ATM-KD stable cell lines were constructed by lentivirus infection and the efficiency was verified by measuring the expression of ATM mRNA and protein level (Fig. 2A\&B). These cells were used to investigate the role of ATM in TMZ chemoresistance. The $50 \%$ inhibitory concentration $\left(\mathrm{IC}_{50}\right)$ of $\mathrm{TMZ}$ for U87 and U251 cells, as determined by MTT assay, was found to be 53.8 $\mu \mathrm{mol} / \mathrm{ml}$ and $113.9 \mu \mathrm{mol} / \mathrm{ml}$ for U87 and U251 cells, respectively (Fig. 2C\&D). Further, we detected the effect of ATM knockdown on the resistance of U87 and U251 cells to TMZ chemotherapy. As shown in Fig. 2E, after ATM knockdown, the resistance of U87 and U251 cells to TMZ chemotherapy was significantly decreased, thus significantly reducing the percentage of cellular apoptosis in response to TMZ treatment $(p<0.01)$ (Table 2). Cell cycle analysis of ATM knockdown U87 and U251 cells in response to TMZ (IC50) chemotherapy was done by flowcytometry. Results revealed a significant decrease in percentage of $\mathrm{G} 1$ phase cells $(P<0.01)$ and increase in $\mathrm{S}$ phase cells $(P<0.05)$ in both the cell lines. Besides, a significantly higher percentage of U251 cells were found in G2/M phase as compared to U87 cells ( $P<$ 0.05 ) (Table 3 and Fig. 2F). ATM knockdown significantly inhibited the apoptosis of U87 and U251 cells in response to TMZ (IC50) chemotherapy $(p<0.01)$ (Fig. 2G). The above results suggests that the ATM knockdown in glioma cells may promote their DNA synthesis and cell division, while inhibiting apoptosis, in response to TMZ chemotherapy.

Table 2

Effects of ATM knockdown on the cell cycle of glioma cell TMZ (IC50) chemotherapy

\begin{tabular}{|lllllll|}
\hline Groups & G1(\%) & $\boldsymbol{P}$ & $\mathbf{S}(\%)$ & $\boldsymbol{P}$ & G2/M(\%) & $\boldsymbol{P}$ \\
\hline U87NC + TMZ & $50.30 \pm 1.58$ & & $28.55 \pm 1.87$ & $21.15 \pm 1.83$ & \\
\hline U87siATM-1 + TMZ & $43.63 \pm 0.13$ & 0.0019 & $32.91 \pm 0.82$ & 0.021 & $23.46 \pm 0.69$ & 0.110 \\
\hline U251NC + TMZ & $48.57 \pm 0.54$ & & $37.09 \pm 0.69$ & & $18.53 \pm 0.48$ & \\
\hline U251 siATM-1 + TMZ & $43.42 \pm 0.38$ & 0.0055 & $38.68 \pm 0.49$ & 0.043 & $20.12 \pm 0.58$ & 0.042 \\
\hline
\end{tabular}

Table 3

The first 10 signaling pathways and the number of genes involve after ATM knockdown

\begin{tabular}{|lll|}
\hline Gene Set & No. of Genes & Significance Probability \\
\hline KEGG_FOCAL_ADHESION & 21 & $2.67 \mathrm{E}-09$ \\
\hline KEGG_ECM_RECEPTOR_INTERACTION & 13 & $1.05 \mathrm{E}-07$ \\
\hline KEGG_PATHWAYS_IN_CANCER & 20 & $2.99 \mathrm{E}-05$ \\
\hline KEGG_LYSOSOME & 11 & $2.79 \mathrm{E}-04$ \\
\hline KEGG_NEUROTROPHIN_SIGNALING_PATHWAY & 11 & $2.98 \mathrm{E}-04$ \\
\hline KEGG_MAPK_SIGNALING_PATHWAY & 16 & $2.98 \mathrm{E}-04$ \\
\hline KEGG_RENAL_CELL_CARCINOMA & 8 & $6.80 \mathrm{E}-04$ \\
\hline KEGG_REGULATION_OF_ACTIN_CYTOSKELETON & 13 & $1.65 \mathrm{E}-03$ \\
\hline KEGG_CELL_ADHESION_MOLECULES_CAMS & 10 & $1.96 \mathrm{E}-03$ \\
\hline KEGG_ETHER_LIPID_METABOLISM & 5 & $5.54 \mathrm{E}-03$ \\
\hline
\end{tabular}

ATM silencing induced TMZ chemotherapy resistance of glioma, in vivo. A subcutaneous xenograft tumor model of ATM knockdown glioma cells was constructed in nude mice, to further study the molecular mechanism in vivo. ATM knockdown could significantly inhibit the tumor growth rate in nude mice, as compared to control group (Fig. 3A-C). Further, in response to TMZ chemotherapy, 3 days after stopping the treatment (the 32nd day after injecting cells), an increase in tumor growth was observed. Tumor volume in the control group decreased to the lowest level on the 10th 
day (the 39th day after injecting cells) after stopping the chemotherapy, but started to increase from the 13th day (the 42nd day after injecting cells). However, nude mice in ATM knockdown group showed little response to TMZ chemotherapy, demonstrated by continued proliferation of the tumor reaching a significantly increase in volume on 10th and 13th day (the 39th day and 42nd day after injecting cells) after stopping TMZ chemotherapy, as compared to the control group $(p<0.05)$, (Fig. 3D).

Screening for ATM knockdown-induced TMZ chemotherapy-resistant genes in glioma. In order to further explore the molecular mechanism of ATM knockdown induced glioma resistance to TMZ chemotherapy, we used human genomewide oligonucleotide microarray to detect the changes of gene expression profile after ATM knockout in U251 cells. Further, using the High Content Screening Cellomics system, the role of differentially expressed genes in U251 cells in response to TMZ chemotherapy and the target genes related to the chemotherapy-resistance caused by ATM knockdown, especially those capable of inducing apoptosis and improving chemotherapy-sensitivity, were screened out. As shown in Fig. 4A, B, C, D, and E, the quality of RNA samples used for gene chip detection and the coincidence degree of each signal distribution curve of the chip data was good, indicating the reliability of the experiment. The interchip correlation coefficients in each group were very close to 1.0, indicating that the data had good repeatability and reliability, and could be used for the screening of downstream differentially expressed genes. The screening criteria for genes with significant differences must be in line with $|F C|>1.5$, and $P<0.05$, and according to this standard, 324 upregulated genes and 402 down-regulated genes were screened out. The two factors of $p$ value and $F C$ value obtained by $T$ test analysis were used to draw the volcano map that highlighted the significant difference between the two groups of sample data. In the volcano map, the $y$-coordinate shows the -Ig p value calculated by T-test, and the x-coordinate shows the $F C$ value after log2 conversion. In the upper left red region, down-regulated genes were expressed, while in the upper right red region, up-regulated genes were expressed (Fig. 4F). Cluster analysis was performed on all differentially expressed genes (Fig. 4G ). In the figure, there was a gene in each row and a specimen in each column. Different colors represented the expression levels of different genes; red represents up-regulation and green represents down-regulation of gene expression, while black represents no difference in gene expression. The expression profiles of the three samples in the U251-NC and U251ATM-KD groups were highly consistent, and the differences between the samples in the U251-NC and U251ATM-KD groups could be clearly distinguished by the color gradient change, indicating the high reliability of these differentially expressed genes screened. We also conducted pathway, molecular function, biological process and cellular component GO analysis of differentially expressed genes after ATM knockdown, sort by $p$ value. Pathway analysis showed the possibility of high correlation of MAPK and tumor-related pathways with this study (Fig. 4H, Table 4). Molecular function GO analysis showed that ATM is mainly related to the function of DNA binding, transcription-related factor activity, transcription factor binding, receptor binding, $\mathrm{G}$ protein and small $\mathrm{G}$ protein regulatory active molecules (Fig. 4I, Table 5). Biological process $\mathrm{GO}$ analysis showed that ATM is mainly involved in biological processes, including intracellular signal transduction, tissue and organ development, negative regulation of cellular biological processes, and gene transcription (Fig. 4J, Table 6). Cellular component GO analysis showed that ATM knockdown induced differentially expressed genes were composed of cellular components, including cytoplasmic proteins and membrane related proteins (Fig. 4K, Table 7). 
Table 4

The first 10 Molecular functional gene set and the number of genes involve after ATM knockdown

\begin{tabular}{|lll|}
\hline Gene Set & No. of Genes & Significance Probability \\
\hline DNA_BINDING & 37 & $5.40 \mathrm{E}-10$ \\
\hline TRANSCRIPTION_FACTOR_ACTIVITY & 24 & $3.53 \mathrm{E}-07$ \\
\hline TRANSCRIPTION_REPRESSOR_ACTIVITY & 14 & $1.40 \mathrm{E}-05$ \\
\hline TRANSCRIPTION_COREPRESSOR_ACTIVITY & 11 & $2.15 \mathrm{E}-05$ \\
\hline RECEPTOR_BINDING & 21 & $3.92 \mathrm{E}-05$ \\
\hline SMALL_GTPASE_REGULATOR_ACTIVITY & 9 & $5.58 \mathrm{E}-05$ \\
\hline HEPARIN_BINDING & 6 & $5.74 \mathrm{E}-05$ \\
\hline GTPASE_REGULATOR_ACTIVITY & 11 & $1.88 \mathrm{E}-04$ \\
\hline TRANSCRIPTION_FACTOR_BINDING & 17 & $2.83 \mathrm{E}-04$ \\
\hline GLYCOSAMINOGLYCAN_BINDING & 6 & $4.31 \mathrm{E}-04$ \\
\hline
\end{tabular}

Table 5

The first 10 biological process gene set and the number of genes involve after ATM knockdown

\begin{tabular}{|lcc|}
\hline Gene Set & $\begin{array}{c}\text { No. of } \\
\text { Genes }\end{array}$ & $\begin{array}{c}\text { Significance } \\
\text { Probability }\end{array}$ \\
\hline SIGNAL_TRANSDUCTION & 79 & $2.21 \mathrm{E}-16$ \\
\hline MULTICELLULAR_ORGANISMAL_DEVELOPMENT & 61 & $3.32 \mathrm{E}-16$ \\
\hline ANATOMICAL_STRUCTURE_DEVELOPMENT & 57 & $1.17 \mathrm{E}-14$ \\
\hline NEGATIVE_REGULATION_OF_BIOLOGICAL_PROCROCESS & 46 & $1.17 \mathrm{E}-14$ \\
\hline NEGATIVE_REGULATION_OF_CELLULAR_PROCESCESS & 44 & $4.14 \mathrm{E}-14$ \\
\hline SYSTEM_DEVELOPMENT & 50 & $1.84 \mathrm{E}-13$ \\
\hline NUCLEOBASENUCLEOSIDENUCLEOTIDE_AND_NUCNUCLEIC_ACID_METABOLIC_PROCESS & 60 & $9.39 \mathrm{E}-13$ \\
\hline BIOPOLYMER_METABOLIC_PROCESS & 71 & $2.10 \mathrm{E}-12$ \\
\hline TRANSCRIPTION & 44 & $5.28 \mathrm{E}-12$ \\
\hline ESTABLISHMENT_OF_LOCALIZATION & 44 & $6.14 \mathrm{E}-10$ \\
\hline
\end{tabular}


Table 6

The first 10 cellular component gene set and the number of genes involve after ATM knockdown

\begin{tabular}{|lll|}
\hline Gene Set & No. of Genes & Significance Probability \\
\hline CYTOPLASM & 102 & $4.08 \mathrm{E}-22$ \\
\hline MEMBRANE & 91 & $2.02 \mathrm{E}-18$ \\
\hline NUCLEUS & 72 & $1.05 \mathrm{E}-16$ \\
\hline INTEGRAL_TO_MEMBRANE & 64 & $6.22 \mathrm{E}-14$ \\
\hline INTRINSIC_TO_MEMBRANE & 64 & $9.32 \mathrm{E}-14$ \\
\hline MEMBRANE_PART & 71 & $5.26 \mathrm{E}-13$ \\
\hline CYTOPLASMIC_PART & 62 & $2.41 \mathrm{E}-12$ \\
\hline PLASMA_MEMBRANE & 63 & $2.50 \mathrm{E}-12$ \\
\hline INTEGRAL_TO_PLASMA_MEMBRANE & 46 & $7.07 \mathrm{E}-10$ \\
\hline INTRINSIC_TO_PLASMA_MEMBRANE & 46 & $1.02 \mathrm{E}-09$ \\
\hline
\end{tabular}


Table 7

Effects of target gene knockdown on TMZ (IC50) chemotherapy in U251 cells

\begin{tabular}{|c|c|c|c|}
\hline Groups & proliferation rate & Chemotherapy proliferation rate & Chemotherapy inhibition rate(\%) \\
\hline $\mathrm{U} 251 \mathrm{NC}+\mathrm{TMZ}$ & 2.41 & \multirow[t]{2}{*}{0.60} & \multirow[t]{2}{*}{40.05} \\
\hline U251NC & 4.02 & & \\
\hline U251 siATM-1 + TMZ & 3.40 & \multirow[t]{2}{*}{0.90} & \multirow[t]{2}{*}{10.29} \\
\hline U251 SiATM-1 & 3.79 & & \\
\hline U251 siCPA4 + TMZ & 1.13 & \multirow[t]{2}{*}{0.76} & \multirow[t]{2}{*}{24.67} \\
\hline U251 siCPA4 & 1.50 & & \\
\hline U251 siHKDC1 + TMZ & 2.54 & \multirow[t]{2}{*}{0.86} & \multirow[t]{2}{*}{14.48} \\
\hline U251 siHKDC1 & 2.97 & & \\
\hline U251 siMPZL1 + TMZ & 1.89 & \multirow[t]{2}{*}{0.74} & \multirow[t]{2}{*}{26.17} \\
\hline U251 siMPZL1 & 2.56 & & \\
\hline U251 siNME4 + TMZ & 1.67 & \multirow[t]{2}{*}{0.82} & \multirow[t]{2}{*}{17.73} \\
\hline U251 SiNME4 & 2.03 & & \\
\hline U251 siPGM2L1 + TMZ & 2.53 & \multirow[t]{2}{*}{0.80} & \multirow[t]{2}{*}{20.44} \\
\hline U251 siPGM2L1 & 3.18 & & \\
\hline U251 siTNFAIP2 + TMZ & 3.15 & \multirow[t]{2}{*}{0.72} & \multirow[t]{2}{*}{28.57} \\
\hline U251 siTNFAIP2 & 4.41 & & \\
\hline U251 siTNFRSF21 + TMZ & 2.10 & \multirow[t]{2}{*}{0.74} & \multirow[t]{2}{*}{26.32} \\
\hline U251 siTNFRSF21 & 2.85 & & \\
\hline U251 siUSP18 + TMZ & 1.15 & \multirow[t]{2}{*}{0.63} & \multirow[t]{2}{*}{37.16} \\
\hline U251siUSP18 & 1.83 & & \\
\hline U251 siUSP25 + TMZ & 2.28 & \multirow[t]{2}{*}{0.68} & \multirow[t]{2}{*}{31.32} \\
\hline U251 siUSP25 & 3.32 & & \\
\hline U251 siRBFOX2 + TMZ & 2.61 & \multirow[t]{2}{*}{0.55} & \multirow[t]{2}{*}{55.18} \\
\hline U251 siRBFOX2 & 4.73 & & \\
\hline U251 siARHGAP29 + TMZ & 2.86 & \multirow[t]{2}{*}{0.65} & \multirow[t]{2}{*}{34.85} \\
\hline U251siARHGAP29 & 4.39 & & \\
\hline U251 siZNF404 + TMZ & 3.07 & \multirow[t]{2}{*}{0.65} & \multirow[t]{2}{*}{35.23} \\
\hline U251 siZNF404 & 4.74 & & \\
\hline U251 silFIT1 + TMZ & 2.08 & \multirow[t]{2}{*}{0.91} & \multirow[t]{2}{*}{8.77} \\
\hline U251 silFIT1 & 2.28 & & \\
\hline U251 siTNFSF18 + TMZ & 2.13 & 0.76 & 23.93 \\
\hline
\end{tabular}




\begin{tabular}{|lllc|}
\hline Groups & proliferation rate & Chemotherapy proliferation rate & Chemotherapy inhibition rate(\%) \\
\hline U251 siTNFSF18 & 2.80 & & 45.11 \\
\hline U251 siDCP2 + TMZ & 2.64 & 0.55 & \\
\hline U251 siDCP2 & 4.81 & & 17.63 \\
\hline U251 siBNIP3L + TMZ & 2.43 & 0.82 & \\
\hline U251 siBNIP3L & 2.95 & & \\
\hline
\end{tabular}

Screening and identification of genes related to ATM knockdown induced TMZ chemotherapy resistance of glioma. After ATM knockdown, differentially expressed genes were screened to enter the downstream test according to the following criteria: differentially expressed new genes with $p<0.05$ and $\mid F C />1.5$, whose functions were not fully defined, remove multiple transmembrane protein genes, and remove genes with unknown functions. For the 402 down-regulated genes, 19 genes were preliminarily screened by the screening criteria, and the relative expressions of 19 candidate genes in U251 cells were detected by qRT-PCR (Fig. 5A). In order to identify the role of 19 candidate genes in glioma TMZ chemotherapy, RNA interference of multiple targets was performed on each of them, and stable lentivirus knockdown cell lines were constructed. CDC23, RAC1 and CD164, which were less than 70\% of the fluorescence efficiency after lentivirus infection, were not considered further and a total of 16 genes were finally detected downstream. High content screening Cellomics system (HCS) was used to detect the effect of candidate gene RNA interference on TMZ treated U251 cell, the cell proliferation, chemotherapy proliferation rate and chemotherapy inhibition rate after 5 days of chemotherapy (Table 8); U251-NC was used as negative control and U251-ATM-KD-1 was used as positive control. Among the 16 candidate genes, 14 had lower chemotherapy inhibition rate than the negative control (40.05\%). Among them, the candidate genes that were close to the positive control U251-ATM-KD-1 (10.29\%) and might be related to apoptosis are: IFIT1 (the inhibition rate of TMZ chemotherapy was 8.77\%), BNIP3L (the inhibition rate of TMZ chemotherapy was $17.63 \%$ ), and NME4 (the inhibition rate of TMZ chemotherapy was $17.73 \%$ ). The 96 -well plate was scanned and read at the same time point and in the same field for 5 consecutive days, image collection and data analysis were conducted, and the scan images (Fig. 5B) and cell count values of the 5 days of TMZ (IC50) chemotherapy of the three candidate gene knockdown cells were obtained. U251-NC was used as the negative control, and U251-ATM-KD-1 was used as the positive control. As shown in Fig. 5C, D and E, after knockdown of IFIT1, BNIP3L and NME4 respectively, the proliferation of U251 cells in TMZ (IC50) were all higher than those in U251-NC group. Of these, IFIT1 showed the highest response, which was equivalent to the positive control U251-ATM-KD-1. Therefore, in order to reveal the molecular mechanism of ATM knockdown induced resistance to TMZ chemotherapy of glioma, we choose IFIT1 for in-depth study.

Table 8

Effects of IFIT1 knockdown on the cell cycle of glioma cell TMZ (IC50) chemotherapy

\begin{tabular}{|lllllll|}
\hline Groups & G1(\%) & $\boldsymbol{p}$ & $\mathbf{S}(\%)$ & $\boldsymbol{p}$ & G2/M(\%) & $\boldsymbol{p}$ \\
\hline U251NC + TMZ & $28.38 \pm 3.9$ & & $44.49 \pm 4.52$ & & $27.13 \pm 2.52$ & \\
\hline U251 silFIT1 + TMZ & $5.77 \pm 0.86$ & 0.000013 & $56.54 \pm 5.31$ & 0.0022 & $37.69 \pm 3.46$ & 0.0004 \\
\hline U87NC + TMZ & $31.12 \pm 4.3$ & & $45.56 \pm 3.8$ & & $23.32 \pm 3.52$ & \\
\hline U87silFIT1 + TMZ & $10.25 \pm$ & 0.0001 & $57.53 \pm 5.1$ & 0.00355 & $32.22 \pm 3.87$ & 0.00108 \\
\hline
\end{tabular}

Role of IFIT1 in glioma cell TMZ chemotherapy. In order to further verify the role of IFIT1 gene in glioma's resistance to TMZ chemotherapy, we used single-target RNA to interfere with the expression of IFIT1 in U251 cells. At first, we detected the expression of IFIT1 in U87, U251, LN229, U373 and HEB cell lines by qRT-PCR and western blot, which revealed an increased expression in all the tested glioma cell lines, as compared to HEB cell line (Fig. 6A and B). Then, 
with lentivirus interference, we constructed U251-IFIT1-KD and U87-IFIT1-KD stable cell lines (Fig. 6C and D). Both regular and knockdown versions of U251 cells were treated with TMZ for 5 days and then assessed for changes in Cell proliferation, clone formation, cell cycle and apoptosis. MTT assay was used to detect the changes in cell proliferation, and as shown in Fig. 6E and F, the proliferation of U251-IFIT1-KD cells was higher than that of the control U251-NC cells. On the 5th day of TMZ treatment, the inhibition rate of chemotherapy on U251-IFIT1-KD group $(15.3 \pm 3.2 \%)$ was significantly lower than that of the negative control group $(29.3 \pm 6.6 \%),(p<0.05)$. Meanwhile, a similar suppression in the inhibition rate of TMZ chemotherapy was also seen in U87 cells (Fig. 6G, $P<0.05$ ). Further, the number of clonal formation of U251-IFIT1-KD + TMZ (IC50) and U87-IFIT1-KD + TMZ (IC50) group was significantly less than their respective control cells, (Fig. $6 \mathrm{H}, \mathrm{p}<0.05$ ). FACS method was used to detect cell cycle stage and the results showed that when IFIT1 was knockdown, cells at G1 phase and S phase increased significantly $(p<0.001)$, while proportionally decreasing cells at G2/M phase. This indicates that the IFIT1 knockdown can promote DNA synthesis and cellular proliferation while inducing resistance to TMZ chemotherapy in U251 and U87 cells (Fig. $6 \mathrm{I}$ and Table 9). Annexin v-apc single staining apoptosis analysis showed that the rate of apoptosis of U251/U87-IFIT1-KD + TMZ (IC50) group (6.61 \pm $0.28 \%$ ) was significantly lower than that of the control group $(7.43 \pm 0.41 \%)$ (Fig. $6 \mathrm{~J}, \mathrm{p}<0.001)$. The above results showed that IFIT1 knockdown can significantly promote the proliferation of glioma cells, while inhibiting their apoptosis, thus imparting resistance in glioma cells to TMZ chemotherapy. Thus, IFIT1 may serve as a molecular marker indicating the sensitivity of glioma to TMZ chemotherapy.

Table 9 Correlation of p-ATM, IFIT1 and MGMT expression in glioblastoma

\begin{tabular}{llllllll}
\hline Groups & & \multicolumn{3}{c}{$\mathrm{p}-\mathrm{ATM}$} & \multicolumn{3}{c}{ MGMT } \\
\cline { 3 - 8 } & $\mathrm{n}$ & Low & High & $P$ & Low & High & $P$ \\
\hline IFIT1 & & & & & & & \\
Low & 13 & 13 & 0 & & 7 & 6 & \\
High & 57 & 42 & 15 & 0.037 & 48 & 9 & 0.016 \\
\hline
\end{tabular}

Expression of p-ATM, IFIT1 and MGMT in glioblastoma tissues. Immunohistochemical staining was used to evaluate the expression of p-ATM, IFIT1 and MGMT in tissues obtained from 70 cases of glioblastoma. p-ATM was expressed in the nucleus and/or cytoplasm, and the median expression was $0 \%$ (range 0-30\%), including 55 cases with low expression (Fig. 7A) and 15 cases with high expression (Fig. 7B), IFIT1 was primarily expressed in the cytoplasm, with a median expression of $24 \%$ (range $0-65 \%$ ), including 13 cases with low expression (Fig. 7C) and 57 cases with high expression (Fig. 7D). Further, with 55 cases of low expression and 15 cases of high expression, the median expression of MGMT was found to be $10 \%$ (range $0-50 \%$ ). In addition, the expression of IFIT1 was observed in endothelial cells of certain specimens (Fig. 7E), tumor tissue necrosis area (Fig. 7F), edematous area (Fig. 7G), and around vascular endothelial cells (Fig. 7H). Spearman's analysis revealed a positive correlation between p-ATM and IFIT1 expression ( $r=$ $0.249, p<0.05)$, and a negative correlation between IFIT1 and MGMT expression $(r=-0.288, p<0.05)($ Table 10).

Table 10 Correlation between expression of p-ATM and clinical characteristics

\begin{tabular}{lcccc}
\hline \multicolumn{1}{c}{ Groups } & \multicolumn{5}{c}{$\mathrm{p}-\mathrm{cTM}$} \\
& $\mathrm{n}$ & Low & High & $P$ \\
\hline Gender & & & & \\
Male & 42 & 32 & 10 & \\
Female & 28 & 23 & 5 & 0.555 \\
Surgery Age & & & & \\
$>60$ & 29 & 26 & 3 & \\
$\leq 60$ & 41 & 29 & 12 & 0.059 \\
KPS Score & & & & \\
$>70$ & 44 & 37 & 7 & \\
$\leq 70$ & 26 & 18 & 8 & 0.146 \\
\hline
\end{tabular}


The relationship between the clinical characteristics and expression of p-ATM, IFIT1 and MGMT. Mann-whitney test found no correlation between p-ATM expression and the clinical characteristics, including gender, age and KPS (Table 11). In order to analyze the relationship between the prognosis and expression of p-ATM, we used progression free survival (PFS) and overall survival (OS) as evaluation indicators, by following up 70 patients for a period of 11-154 weeks, median follow-up time was 45 weeks. During this period, tumor progression was observed in 64 cases (91.4\%) and death in 43 cases (61.4\%). Univariate analysis indicated (Table 12) no correlation of ATM expression with neither PFS (Fig. 8A) nor OS (Fig. 8B). Further, we verified the expression of p-AKT and IFIT1 in glioblastoma tissues and their relationship with prognosis. Results found that the IFIT1 was widely expressed in glioblastoma, and the extent of its expression was positively correlated with the expression of p-ATM, and negatively correlated with the expression of MGMT. Increased expression of IFIT1 generally indicates a better prognosis, while the combined analysis of IFIT1 and MGMT is more accurate in predicting the prognosis.

Table 11

Univariate analysis of factors affecting patients' PFS and OS(log-rank test)

\begin{tabular}{|llllllll|}
\hline Groups & cases & PFS & \multicolumn{5}{c|}{ OS } \\
\cline { 3 - 7 } & & Median & $95 \% \mathrm{Cl}$ & $\boldsymbol{P}$ & Median & $95 \% \mathrm{Cl}$ & $\boldsymbol{P}$ \\
\hline Gender & & & & & & & \\
\hline Male & $42(60.0)$ & 27 & $16.4-37.6$ & 56 & $30.7-81.3$ & \\
\hline Female & $28(40.0)$ & 24 & $11.9-36.1$ & 0.934 & 44 & $28.9-59.1$ & 0.550 \\
\hline ATM & & & & & & & \\
\hline Low & $55(78.6)$ & 28 & $19.1-36.9$ & & 53 & $36.8-69.2$ & \\
\hline High & $15(21.4)$ & 23 & $14.1-31.9$ & 0.730 & 38 & $25.8-50.2$ & 0.762 \\
\hline
\end{tabular}


Table 12

The primer sequences for PCR.

\begin{tabular}{|c|c|c|}
\hline Names & primers & Sequences $\left(5^{\prime}-3^{\prime}\right)$ \\
\hline \multirow[t]{2}{*}{ GAPDH } & Forward & TGACTTCAACAGCGACACCCA \\
\hline & Reverse & CACCCTGTTGCTGTAGCCAAA \\
\hline \multirow[t]{2}{*}{ ATM } & Forward & CCACCAGAATCTCAAGGAATCAC \\
\hline & Reverse & AGTAGCAGCCAAGGACACC \\
\hline \multirow[t]{2}{*}{ ARHGAP29 } & Forward & GACTTTCATCGAAAACTTCCACG \\
\hline & Reverse & AATTTGCGAAACTTGTGTGTGAG \\
\hline \multirow[t]{2}{*}{ BNIP3L } & Forward & TTGGATGCACAACATGAATCAGG \\
\hline & Reverse & TCTTCTGACTGAGAGCTATGGTC \\
\hline \multirow[t]{2}{*}{ CDC23 } & Forward & CATGGCTGCAATAGCAAGAAAG \\
\hline & Reverse & CGCCTCATTTTTCACTTGTCCT \\
\hline \multirow[t]{2}{*}{ DCP2 } & Forward & TTGTGCTGCTAGAGAGGTCTT \\
\hline & Reverse & GAGAACCACTCAATGTTCCGAAT \\
\hline \multirow[t]{2}{*}{ IFIT1 } & Forward & GCGCTGGGTATGCGATCTC \\
\hline & Reverse & CAGCCTGCCTTAGGGGAAG \\
\hline \multirow[t]{2}{*}{ RAC1 } & Forward & ATGTCCGTGCAAAGTGGTATC \\
\hline & Reverse & CTCGGATCGCTTCGTCAAACA \\
\hline \multirow[t]{2}{*}{ RBFOX2 } & Forward & GACGCAATGGTTCAGCCTTTT \\
\hline & Reverse & GCGTACTTCCGTAGAGTGTCAG \\
\hline \multirow[t]{2}{*}{ TNFSF18 } & Forward & AGCCATTCAAGAACTCAAGGAG \\
\hline & Reverse & AGGAGGTTCAGAAGATGCCATT \\
\hline \multirow[t]{2}{*}{ ZNF404 } & Forward & AAGTAAATGCGTACCATCAGGAG \\
\hline & Reverse & TCCCACTTTAGGTCTCTGTTGT \\
\hline \multirow[t]{2}{*}{ CD164 } & Forward & CAGTGCCTTAGAAGACAGTGAA \\
\hline & Reverse & AAGTTACATCCTCTGACCAАTCC \\
\hline \multirow[t]{2}{*}{ CPA4 } & Forward & AGGTGGATACTGTTCATTGGGG \\
\hline & Reverse & TTGCTGATCTCGTCTCCATTTC \\
\hline \multirow[t]{2}{*}{ HKDC1 } & Forward & TGAGCCGTCTGACCAAAGC \\
\hline & Reverse & TAGGGGTCGTCATAGGCACA \\
\hline \multirow[t]{2}{*}{ MPZL1 } & Forward & ACGCCAAAAGAAATCTTCGTGG \\
\hline & Reverse & TCAACCCGCCAGTCGTACTA \\
\hline NME4 & Forward & AGGGTACAATGTCGTCCGC \\
\hline
\end{tabular}

Page 13/27 


\begin{tabular}{|lll|}
\hline Names & primers & Sequences $\left(\mathbf{5}^{\prime} \mathbf{~} \mathbf{3}^{\prime}\right.$ ) \\
\hline PGM2L1 & Reverse & GACGCTGAAGTCACCCCTTAT \\
& Forward & CGAGATCGTCTTTGTTGCCGA \\
\cline { 2 - 3 } TNFAIP2 & Reverse & AGCCTCTCTGCTTGAAGTCTG \\
\cline { 2 - 3 } & Reverse & CCCGCTTTATCTGTGAGCCC \\
\hline TNFRSF21 & Forward & TTGACTGACCGAGAATGCACT \\
\cline { 2 - 3 } & Reverse & TTCATCACACTAGAAGGCACATC \\
\hline USP18 & Forward & CAGTCTGGAGGGCAGTATGAG \\
& Reverse & GGCATTTCCATTAGCACTCC \\
\hline USP25 & Forward & GCACCAGCAGACGTTTTTGAA \\
\cline { 2 - 3 } & Reverse & AGCATTCTTCGCAGTAAGGAAA \\
\hline
\end{tabular}

\section{Discussion}

Temozolomide (TMZ) is currently the first-line chemotherapy drug for malignant glioma, which can significantly improve the survival period of patients $[14,15]$. However, resistance to $T M Z$ is a major issue that can impair the prognosis of the patient. Previous studies have shown that MGMT plays an important role in TMZ resistance [16, 17]. Activation of MGMT depends on DDR initiation, and ATM is a key regulator of DDR [6]. It is known that the activation of ATM leads to cell cycle arrest and repair of damaged DNA. Mohanty $S$ et al. found that the chemotherapeutic resistance of non-small cell lung cancer $\mathrm{H} 460$ cells, to alkylating agent chemotherapy, significantly increased after down-regulation of ATM [18]. Zhou Y et al. found that inhibiting ATM increased the resistance of colorectal cancer cells to oxaliplatin chemotherapy [19]. Dixit D et al. found that high ROS can induce apoptosis in glioma cells by activating ATM and its downstream gene YAP1 [9], but no further research on its association with chemotherapy resistance was conducted. Nadkarni $A$ et al. found that ATM knockdown in U87 and U251 cells inhibited their susceptibility to TMZ-induced apoptosis, thus demonstrating their increased resistance to TMZ (IC50) chemotherapy [21]. Therefore, we infer that ATM can mediate TMZ induced apoptosis in glioma cells, inhibition of which can result in resistance to TMZ chemotherapy. In line with the above inference, we observed a similar result in our in vitro and in vivo experiments. ATM knockdown cells demonstrated continued cellular proliferation and decreased apoptosis to TMZ chemotherapy in in vitro studies. In vivo, in response to TMZ chemotherapy, the tumor growth was significantly inhibited and the tumor volume decreased to the minimum on the 10th day after stopping chemotherapy in the control group. However, in the ATM knockdown group the tumor growth gradually increased, and reached a significantly higher volume than control group on the same 10 th day after the cessation of chemotherapy $(p<0.05)$. This indicates that the suppression of ATM in glioma cells can induce resistance to $\mathrm{TMZ}$ chemotherapy.

ATM plays an important role in promoting cell proliferation. It is found that the expression of ATM is up-regulated in the proliferating cells $[22,12]$. Studies have shown that ATM can activate the Akt pathway $[22,12]$, and PI3K/Akt pathway is a known initial factor of tumorigenesis that can further promote the proliferation and survival of tumor cells [23]. ATM is also shown to promote the migration and invasion of glioma cells through Akt, extracellular regulatory protein kinase and other pathways [24-26]. 
ATM is one of the central regulator of the DNA damage response pathway that can initiate phosphorylation of key proteins leading to cell cycle arrest, DNA repair or apoptosis $[7,8]$. Increased expression of ATM can not only promote cellular apoptosis, but can also activate cascade of genes that contributes to cell cycle arrest $[6,21,25,27,28]$. Similarly, activated ATM can regulate the downstream signal pathway through different pathways and thus plays different roles. Many studies show that the activation of ATM can induce resistance to chemotherapy in various tumors. p-ATM can activate checkpoint kinase 2 (Chk2), phosphorylate the cell division cycle 25 (Cdc 25) protein on serine 216 and deactivate $\mathrm{Cdc} 2$ by phosphorylation, further preventing it from forming an active complex with cyclin B1. These results in cell cycle arrest at G2/M phase, repairs damaged DNA, and also impart resistance to tumor cells against alkylating agents [20]. Other studies have shown that ATM can activate p53 directly or through Chk2 [7, 29, 30], and then activate p21 to inhibit the activation of Cdc2 [7,31], leading to cell cycle arrest at G2/M phase and chemotherapy resistance against alkylating agents. Eich $M$ et al. [4] found that ATM knockdown can improve the sensitivity of glioblastoma cell LN229 to TMZ chemotherapy. Some studies have also found that ATM inhibitors can further enhance the chemotherapy-sensitivity of TMZ-sensitive glioma cell lines [20], and can reverse their drug resistance to TMZ by weakening the autophagy [27].

Under different microenvironments, DNA damage caused by alkylating agents can activate different ATM signal pathways that may reverse the effects. ATM can thus be considered as the switch of the downstream signal pathway; when the switch points to the apoptosis pathway, the expression of ATM can induce apoptosis and make cells sensitive to chemotherapy, and on the contrary, it can also lead to cell cycle arrest, repair damaged DNA and render cells resistant to drugs. Mohanty S et al. [18] found how reactive oxygen species (ROS) can transform tumors between being chemotherapy-sensitive and being drug resistant. The low ROS environment can activate PIASY that can activate IKKY, which when combined with ATM, activate NFK $\beta$ making the tumor more resistant to chemotherapy. On the contrary, a high ROS environment suppress PIASY activity and IKKY-ATM binding, leading to inactivation of downstream NFK $\beta$ and recovery of ATM/Jun amino terminal kinase (JNK) mediated apoptosis pathway, thereby restoring tumor chemosensitivity. Jiang H's et al. found that under non-functioning p53, inhibiting ATM increased the sensitivity of the glioma to genotoxic chemotherapy drugs. But, when p53 was functioning normallyl, inhibiting ATM rendered the tumor resistant to chemotherapy [25].

ATM activation in glioma exhibit dual characteristics: (a) inducing repair pathway that imparts resistance against chemotherapy and (b) inducing apoptosis pathway that improves sensitivity to chemotherapy. In the current study, the IFIT1 gene, an interferon (IFN) stimulated gene (ISG), was chosen to study the mechanisms of ATM-knockdown induced resistance to TMZ chemotherapy in glioma. Studies have shown that DNA damage can induce the activation of IFN signal pathway by activating ATM [32], and can also promote the expression of ISGs by activating IFN regulatory factors (IRFs) [33, 34]. IFIT1 also has the function of promoting apoptosis [34, 35]. Human IFIT family includes IFIT1/ISG56, IFIT2/ISG54, IFIT3/ISG60 and IFIT5/ ISG58, all of which are located on chromosome 10 [37]. Studies have shown that activated ATM can promote the expression of IFN that can further promote the expression of ISGs through IRF1 and IRF7 [33, 34]. IFIT family genes are involved in biological processes related to translation initiation, virus replication, double-stranded RNA signal transduction, cell migration and proliferation [37-39]. The current studies on IFIT1 largely focus on its antiviral aspects [37, 40,41], with few studies studying its role in cancer. In the present study, the expression of IFIT1 in glioma U251 cells was verified at the RNA and protein levels. On down-regulation of IFIT1 in U251 glioma cells, an inhibition in cellular apoptosis, increased DNA synthesis, accelerated cell proliferation and increased clone formation of U251 cells was observed. Further, resistance of U251 cells to TMZ chemotherapy was also observed, suggesting IFIT1 as a possible molecular marker indicating the sensitivity of glioma to TMZ chemotherapy.

The endogenous expression of IFN in glioblastoma cells can be enhanced by various factors, including ATM [32-34, 42]. IFN can induce the expression of IFIT1 [43], and also can improve tumor sensitivity to chemotherapy by inhibiting 
the expression of MGMT [44-46]. Our study found that the expression of IFIT1 in glioblastoma was negatively correlated with MGMT expression, which we speculated to be related to IFN activity, and needs to be studied further.

The current understanding on the role of ATM in glioma chemotherapy has a problem that we can't predict whether activated ATM in glioma after TMZ chemotherapy induces chemoresistance through DNA repair pathway, or improves chemo-sensitivity by inducing apoptosis. With such double-edged characteristics of ATM, it is particularly important to screen the downstream genes induced by ATM to better our understanding of the possible outcome. Clinically, the resistance of glioma to TMZ chemotherapy can be effectively reversed by regulating these genes. Our study starts with the key gene ATM at DNA damage checkpoint, and found that ATM could promote apoptosis by inducing the expression of IFIT1, and improved the sensitivity of TMZ chemotherapy of glioma, thus improving the prognosis of glioma patients.

\section{Conclusion}

Our study investigated the role of ATM in TMZ chemotherapy-resistant glioma, in vitro and in vivo. Post ATM knockdown, the changes in the whole genome expression profile of glioma U251 cells revealed that suppressing ATM could promote resistance to TMZ in glioma by inhibiting IFIT1 expression. This elucidates the underlying mechanism of ATM-regulation mediated development of resistance to TMZ chemotherapy in glioma. Further, we found that p-ATM, IFIT1 and MGMT expression are closely related to the prognosis of glioma patients; especially increased expression of IFIT1 indicates a better prognosis and combination of IFIT1 and MGMT is more accurate in predicting the prognosis. Thus, ATM, IFIT1 and MGMT can serve as molecular markers to predict glioma's sensitivity to TMZ chemotherapy and patient prognosis.

\section{List Of Abbreviations}

ATM : ataxia-telangiectasia mutated; TMZ: Temozolomide; MGMT: O6- methyl guanine DNA methyltransferase; AT: Ataxia-telangiectasia; DDR: DNA damage response; IFIT1: Interferon-induced protein with tetratricopeptide repeat1.

\section{Declarations}

\section{Informed consent}

All the authors agreed to the final manuscript.

\section{Authors' contributions}

LZ conceived and designed most experiments, YLand LZ developed the methodology, YL and ZJ performed most experiments, WS did the analysis and interpretation of data, YL and ZJ wrote the manuscript, $L Z$ and $Y L$ provided financial support.

\section{Funding}

This work was supported by the National Natural and Science Foundation of China (NSFC, Grant No.21435002) and Fujian Medical University Academic Development Fund (Grant No.JS15006).

\section{Availability of data and materials}

All authors ensure that our data does not contain any of the following:

(a) Infringes or makes unauthorized use of the Intellectual Property Rights or any other right of any person; 
(b) Is defamatory, derogatory, discriminatory, or violates any rights of privacy;

(c) Breaches any applicable law or regulation;

(d) Contains a virus, malware, or other potentially harmful component, information, or instructions;

(e) Is indecent, obscene, or offensive.

\section{Ethics approval and consent to participate}

The present study was approved by the Ethics Committee of The Sanbo Brain Hospital of Capital Medical University. The parents of the patients provided written informed consent.

\section{Patient consent for publication}

The pathological specimens and relevant information of the patients used in this study have been asked the patient for consent, and provided written informed consent.

\section{Competing interests}

The authors declare that they have no competing interests.

\section{References}

1. Su YK, Bamodu OA, Tzeng YM, Hsiao M, Yeh CT, Lin CM. Ovatodiolide inhibits the oncogenicity and cancer stem cell-like phenotype of glioblastoma cells, as well as potentiate the anticancer effect of temozolomide. Phytomedicine. 2019;61:152840.

2. Yang LJ, Zhou CF, Lin ZX. Temozolomide and radiotherapy for newly diagnosed glioblastoma multiforme: a systematic review. Cancer Invest. 2014;32:31-6.

3. Zanotto-Filho A, Braganhol E, Klafke K, Figueiró F, Terra SR, Paludo FJ, Morrone M, Bristot IJ, Battastini AM, Forcelini $\mathrm{CM}$, et al. Autophagy inhibition improves the efficacy of curcumin/temozolomide combination therapy in glioblastomas. Cancer Lett. 2015;358:220-31.

4. Chen H, Li X, Li W, Zheng H. miR-130a can predict response to temozolomide in patients with glioblastoma multiforme, independently of 06-methylguanine-DNA methyltransferase. J Transl Med. 2015;13:69.

5. Fukushima T, Takeshima H, Kataoka H. Anti-glioma therapy with temozolomide and status of the DNA-repair gene MGMT. Anticancer Res. 2009;29:4845-54.

6. Eich M, Roos WP, Nikolova T, Kaina B. Contribution of ATM and ATR to the resistance of glioblastoma and malignant melanoma cells to the methylating anticancer drug temozolomide. Mol Cancer Ther. 2013;12:2529-40.

7. Lavin MF, Kozlov S. ATM activation and DNA damage response. Cell cycle. 2007;6:931-42.

8. Derheimer FA, Kastan MB. Multiple roles of ATM in monitoring and maintaining DNA integrity. FEBS Lett. 2010;584:3675-81.

9. Rotman G, Shiloh Y. ATM: from gene to function. Hum Mol Genet. 1998;7:1555-63.

10. Savitsky K, Platzer M, Uziel T, Gilad S, Sartiel A, Rosenthal A, Elroy-Stein O, Shiloh Y, Rotman G. Ataxiatelangiectasia: structural diversity of untranslated sequences suggests complex post-transcriptional regulation of ATM gene expression. Nucleic Acids Res. 1997;25:1678-84.

11. Ditch S, Paull TT. The ATM protein kinase and cellular redox signaling: beyond the DNA damage response. Trends Biochem Sci. 2012;37:15-22. 
12. Halaby MJ, Hibma JC, He J, Yang DQ. ATM protein kinase mediates full activation of Akt and regulates glucose transporter 4 translocation by insulin in muscle cells. Cell Signalling. 2008;20:1555-63.

13. Livak S. Analysis of relative gene expression data using real-time quantitative PCR and the 2- $\Delta \Delta \mathrm{Ct}$ method. Methods. 2001;25:402-8.

14. Villano JL, Seery TE, Bressler LR. Temozolomide in malignant gliomas: current use and future targets. Cancer Chemother Pharmacol. 2009;64:647-55.

15. Macdonald DR, Kiebert G, Prados M, Yung A, Olson J. Benefit of temozolomide compared to procarbazine in treatment of glioblastoma multiforme at first relapse: effect on neurological functioning, performance status, and health related quality of life. Cancer Invest. 2005;23:138-44.

16. Qiu ZK, Shen D, Chen YS, Yang QY, Guo CC, Feng BH, Chen ZP. Enhanced MGMT expression contributes to temozolomide resistance in glioma stem-like cells. Chin J Cancer. 2014;33:115-22.

17. Jiang G, Wei ZP, Pei DS, Xin Y, Liu YQ, Zheng JN. A novel approach to overcome temozolomide resistance in glioma and melanoma: Inactivation of MGMT by gene therapy. Biochem Biophys Res Commun. 2001;406:311-4.

18. Mohanty S, Saha S, Md S, Hossain D, Adhikary A, Mukherjee S, Manna A, Chakraborty S, Mazumdar M, Ray P, et al. ROS-PIASgamma cross talk channelizes ATM signaling from resistance to apoptosis during chemosensitization of resistant tumors. Cell Death Dis. 2014;5:e1021.

19. Zhou Y, Wan G, Spizzo R, Ivan C, Mathur R, Hu X, Ye X, Lu J, Fan F, Xia L, et al. miR-203 induces oxaliplatin resistance in colorectal cancer cells by negatively regulating ATM kinase. Mol Oncol. 2014;8:83-92.

20. Dixit D, Ghildiyal R, Anto NP, Sen E. Chaetocin-induced ROS-mediated apoptosis involves ATM-YAP1 axis and JNKdependent inhibition of glucose metabolism. Cell Death Dis. 2014;5:e1212.

21. Nadkarni A, Shrivastav M, Mladek AC, Schwingler PM, Grogan PT, Chen J, Sarkaria JN. ATM inhibitor KU-55933 increases the TMZ responsiveness of only inherently TMZ sensitive GBM cells. J Neuro-Oncol. 2012;110:349-57.

22. Viniegra JG, Martínez N, Modirassari P, Hernández Losa J, Parada Cobo C, Sánchez-Arévalo Lobo VJ, Aceves Luquero $\mathrm{Cl}$, Alvarez-Vallina L, Ramón y Cajal S, Rojas JM, et al. Full activation of PKB/Akt in response to insulin or ionizing radiation is mediated through ATM. J Biol Chem. 2005; 280: 4029-4036.

23. Nicholson KM, Anderson NG. The protein kinase B/Akt signalling pathway in human malignancy. Cell Signalling. 2002;14:381-95.

24. Zhang J, Han L, Zhang A, Wang Y, Yue X, You Y, Pu P, Kang C. AKT2 expression is associated with glioma malignant progression and required for cell survival and invasion. Oncol Rep. 2010;24:65-72.

25. Jiang H, Jiang H, Shang X, Wu H, Gautam SC, Al-Holou S, Li C, Kuo J, Zhang L, Chopp M. Resveratrol downregulates $\mathrm{PI3K} / \mathrm{Akt} / \mathrm{mTOR}$ signaling pathways in human U251 glioma cells. J Exp Ther Oncol. 2009;8:25-33.

26. Golding SE, Rosenberg E, Valerie N, Hussaini I, Frigerio M, Cockcroft XF, Chong WY, Hummersone M, Rigoreau L, Menear KA, et al. Improved ATM kinase inhibitor KU-60019 radiosensitizes glioma cells, compromises insulin, AKT and ERK prosurvival signaling, and inhibits migration and invasion. Mol Cancer Ther. 2009;8:2894-902.

27. Zou Y, Wang Q, Li B, Xie B, Wang W. Temozolomide induces autophagy via ATMAMPKULK1 pathways in glioma. Mol Med Rep. 2014;10:411-6.

28. Chow JP, Siu WY, Fung TK, Chan WM, Lau A, Arooz T, Ng CP, Yamashita K, Poon RY. DNA damage during the spindle-assembly checkpoint degrades CDC25A, inhibits cyclin-CDC2 complexes, and reverses cells to interphase. Mol Biol Cell. 2003;14:3989-4002.

29. Shieh SY, Ahn J, Tamai K, Taya Y, Prives C. The human homologs of checkpoint kinases Chk1 and Cds1 (Chk2) phosphorylate p53 at multiple DNA damage-inducible sites. Genes Dev. 2000;14:289-300. 
30. Chehab NH, Malikzay A, Appel M, Halazonetis TD. Chk2/hCds1 functions as a DNA damage checkpoint in G(1) by stabilizing p53. Genes Dev. 2000;14:278-88.

31. Zhang Z, Wang CZ, Du GJ, Qi LW, Calway T, He TC, Du W, Yuan CS. Genistein induces G2/M cell cycle arrest and apoptosis via ATM/p53-dependent pathway in human colon cancer cells. Int J Oncol. 2013;43:289-96.

32. Yu Q, Katlinskaya YV, Carbone CJ, Zhao B, Katlinski KV, Zheng H, Guha M, Li N, Chen Q, Yang T, et al. DNA-damageinduced type I interferon promotes senescence and inhibits stem cell function. Cell Rep. 2015;11:785-97.

33. Mboko WP, Mounce BC, Wood BM, Kulinski JM, Corbett JA, Tarakanova VL. Coordinate regulation of DNA damage and type I interferon responses imposes an antiviral state that attenuates mouse gammaherpesvirus type 68 replication in primary macrophages. J Virol. 2012;86:6899-912.

34. Fang L, Choudhary S, Tian B, Boldogh I, Yang C, Ivanciuc T, Ma Y, Garofalo RP, Brasier AR. Ataxia telangiectasia mutated kinase mediates NF-kappaB serine 276 phosphorylation and interferon expression via the IRF7-RIG-I amplification loop in paramyxovirus infection. J Virol. 2015;89:2628-42.

35. Stawowczyk M, Van Scoy S, Kumar KP, Reich NC. The interferon stimulated gene 54 promotes apoptosi. J Biol Chem. 2011;286:7257-66.

36. Reich NC. A death-promoting role for ISG54/IFIT2. J Interferon Cytokine Res. 2013;33:199-205.

37. Zhou X, Michal JJ, Zhang L, Ding B, Lunney JK, Liu B, Jiang Z. Interferon induced IFIT family genes in host antiviral defense. Int J Biol Sci. 2013;9:200-8.

38. Li Y, Li C, Xue P, Zhong B, Mao AP, Ran Y, Chen H, Wang YY, Yang F, Shu HB. ISG56 is a negative-feedback regulator of virus-triggered signaling and cellular antiviral response. Proc Natl Acad Sci U S A. 2009;106:7945-50.

39. D'Andrea LD, Regan L. TPR proteins: the versatile helix. Trends Biochem Sci. 2003;28:655-62.

40. Pei R, Qin B, Zhang X, Zhu W, Kemper T, Ma Z, Trippler M, Schlaak J, Chen X, Lu M. Interferon-induced proteins with tetratricopeptide repeats 1 and 2 are cellular factors that limit hepatitis B virus replication. $J$ Innate Immun. 2014;6:182-91.

41. Kumar P, Sweeney TR, Skabkin MA, Skabkina OV, Hellen CU, Pestova TV. Inhibition of translation by IFIT family members is determined by their ability to interact selectively with the 5'-terminal regions of cap0-, cap1-and 5'pppmRNAs. Nucleic Acids Res. 2014;42:3228-45.

42. Imaizumi T, Murakami K, Ohta K, Seki H, Matsumiya T, Meng P, Hayakari R, Xing F, Aizawa-Yashiro T, Tatsuta T, et al. MDA5 and ISG56 mediate CXCL10 expression induced by toll-like receptor 4 activation in U373MG human astrocytoma cells. Neurosci Res. 2013;76:195-206.

43. Der SD, Zhou A, Williams BR, Silverman RH. Identification of genes differentially regulated by interferon alpha, beta, or gamma using oligonucleotide arrays. Proc Natl Acad Sci U S A. 1988;95:15623-8.

44. Natsume A, Wakabayashi T, Ishii D, Maruta H, Fujii M, Shimato S, Ito M, Yoshida J. A combination of IFN-beta and temozolomide in human glioma xenograft models: implication of p53-mediated MGMT downregulation. Cancer Chemother Pharmacol. 2008;61:653-9.

45. Natsume A, Ishii D, Wakabayashi T, Tsuno T, Hatano H, Mizuno M, Yoshida J. IFN-beta down-regulates the expression of DNA repair gene MGMT and sensitizes resistant glioma cells to temozolomide. Cancer Res. 2005;65:7573-9.

46. Motomura K, Natsume A, Kishida Y, Higashi H, Kondo Y, Nakasu Y, Abe T, Namba H, Wakai K, Wakabayashi T. Benefits of interferon-beta and temozolomide combination therapy for newly diagnosed primary glioblastoma with the unmethylated MGMT promoter: A multicenter study. Cancer. 2011;117:1721-30.

\section{Figures}

Page 19/27 


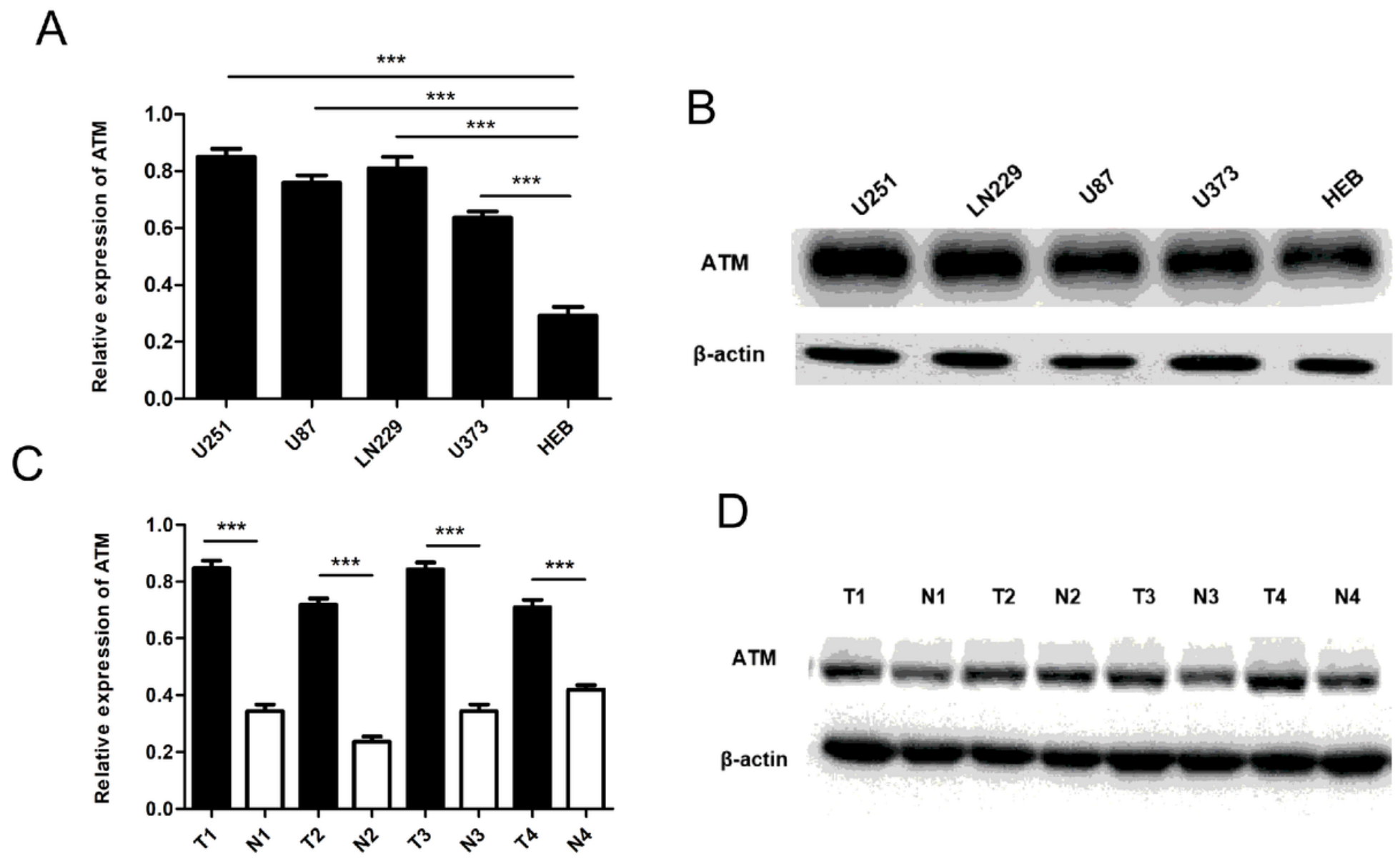

Figure 1

ATM is up-regulated in glioma tissues and cell lines. A. Relative expression of ATM in glioma cell lines U251, U87, LN229, U373 and HEB cells by quantitative qRT-PCR. B. Western blot analysis the expression of ATM in glioma cell lines U251, U87, LN229, U373 and HEB cells. C. qRT-PCR analysis the relative expression of ATM in 4 pairs of glioma tumors compared with their adjacent normal tissues. D. Western blot analysis the expression of ATM in 4 pairs of glioma tumors compared with their adjacent normal tissues. (**P $<0.01$, *** $P<0.001$ ). 
A

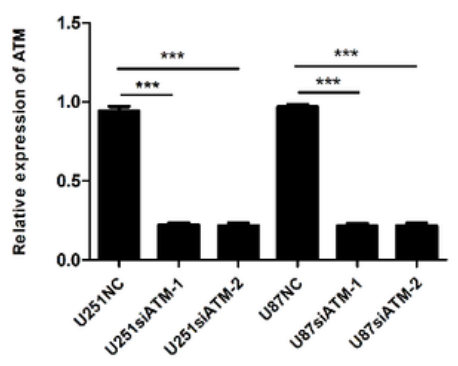

C

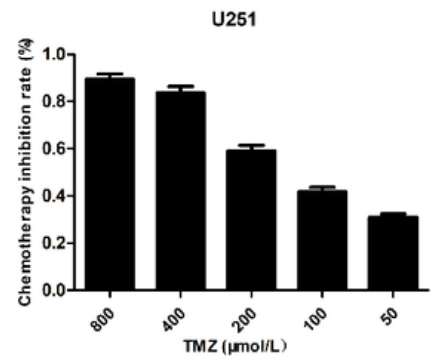

E

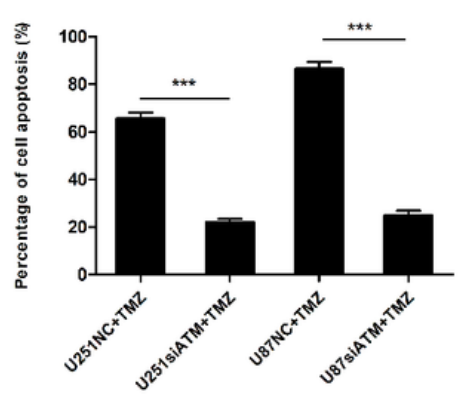

D

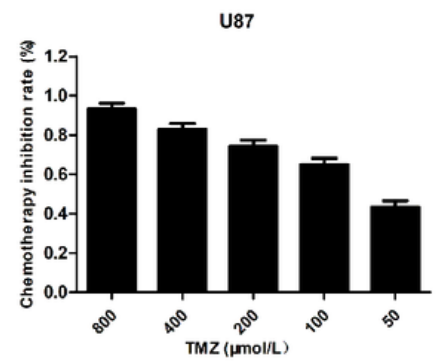

$\mathrm{F}$

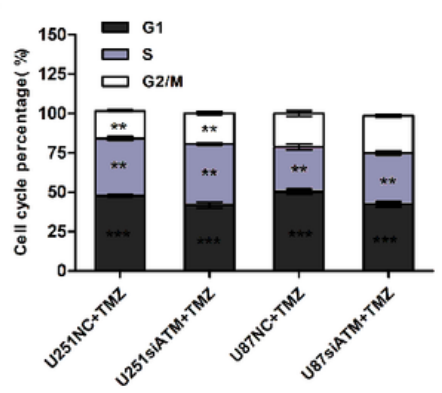

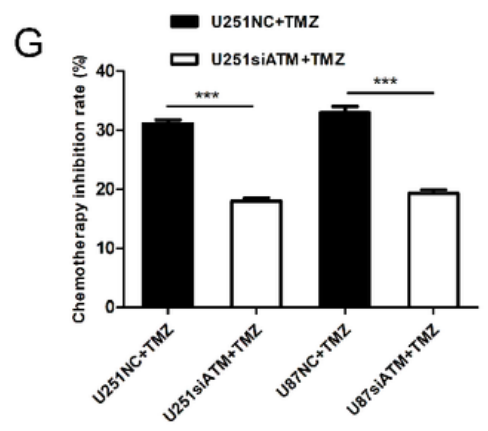

Figure 2

ATM silencing induced TMZ chemotherapy resistance of glioma in vitro. A. qRT-PCR analysis the relative expression of ATM in U251-LV-ATM-KD and U87-LV-ATM-KD stable cell lines. B. Western blot analysis the expression of ATM in U251LV-ATM-KD and U87-LV-ATM-KD stable cell lines. C. The inhibition rate of different concentrations of TMZ on U251 cells. D. The inhibition rate of different concentrations of TMZ on U87 cells. E. The effect of ATM knockdown on the apoptosis of U87 and U251 cells to TMZ chemotherapy. F. The effect of ATM knockdown on the cell cycle of U87 and U251 cells to TMZ chemotherapy. G. The effect of ATM knockdown on the resistance of U87 and U251 cells to TMZ chemotherapy. ( ${ }^{* *} \mathrm{P}<0.01$, $\left.{ }^{\star * *} \mathrm{P}<0.001\right)$. 
A

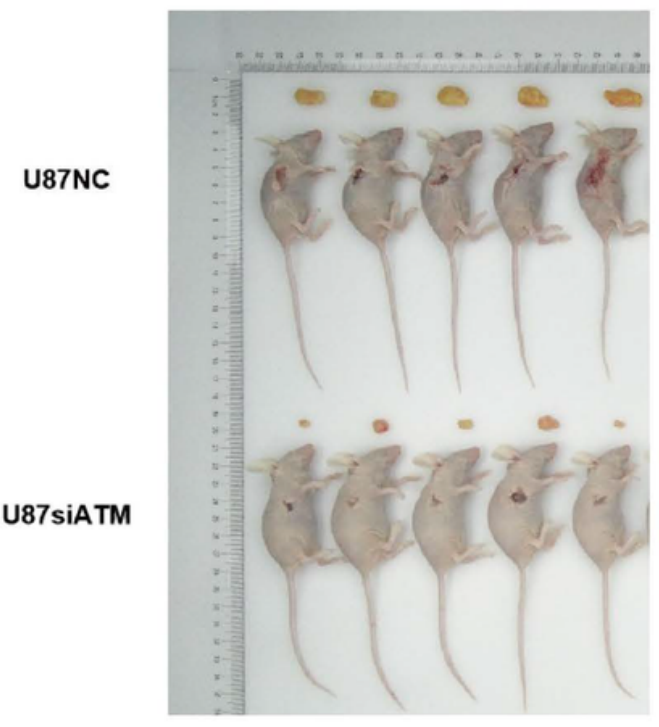

C

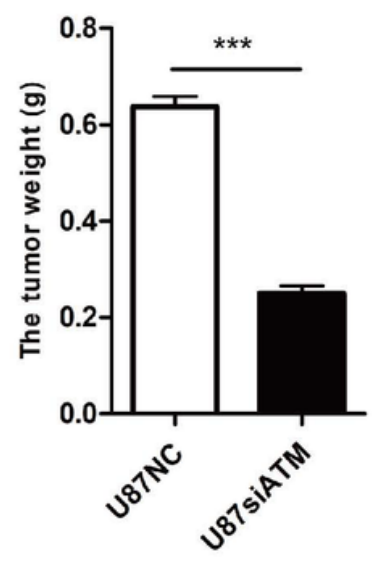

B

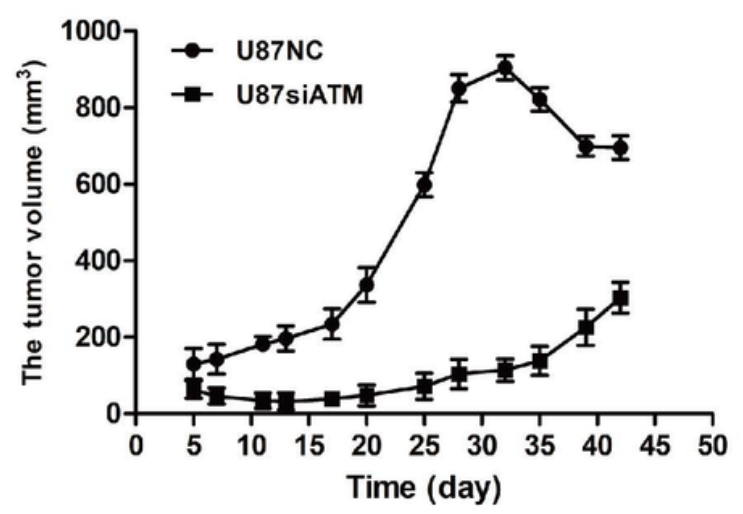

D

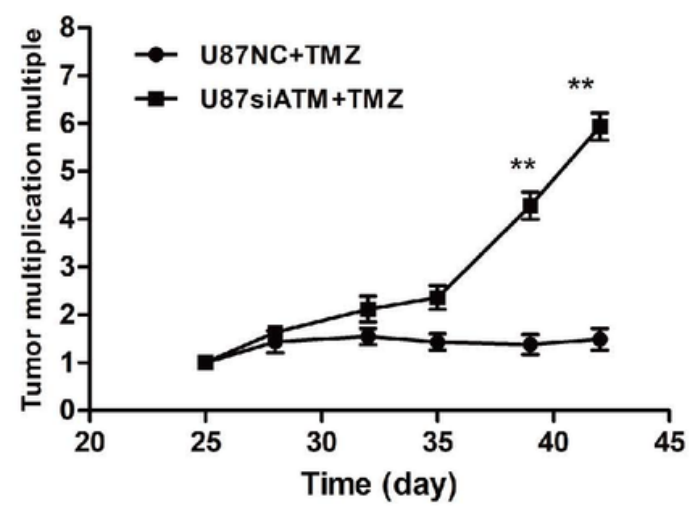

Figure 3

ATM knockdown induced TMZ chemotherapy resistance of glioma in vivo. A. A subcutaneous xenograft tumor model in U87NC cells and U87siATM-1 cells. B. The tumor volume of U87NC cells and U87siATM-1 cells from the 5th day to the 42nd day. C. The tumor weight of U87NC cells and U87siATM-1 cells. D. The influence of ATM knockdown to TMZ chemotherapy in U87NC cells and U87siATM-1 cells. ( $\left.{ }^{*} \mathrm{P}<0.01, * \star * P<0.001\right)$. 
A

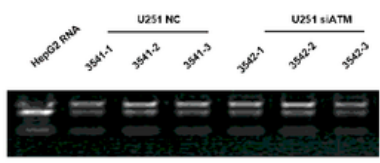

C

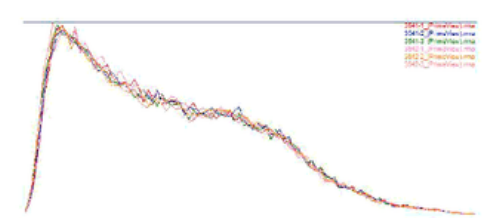

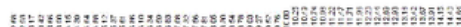
ํ.

E

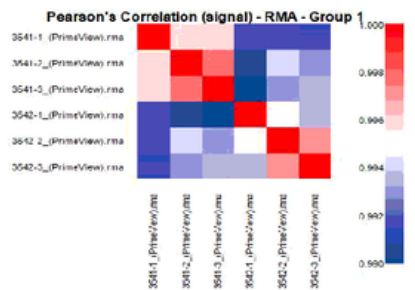

G

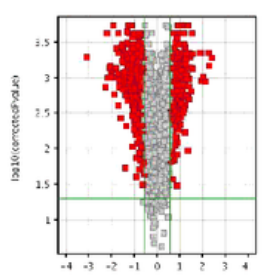

1052 ford cranget)

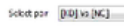

I

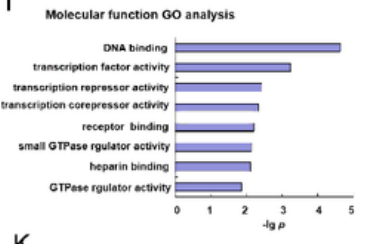

K

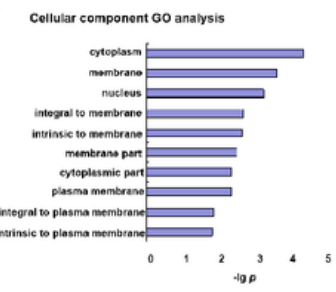

B

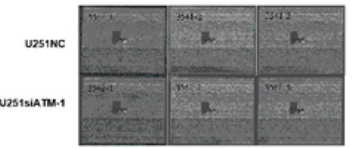

D

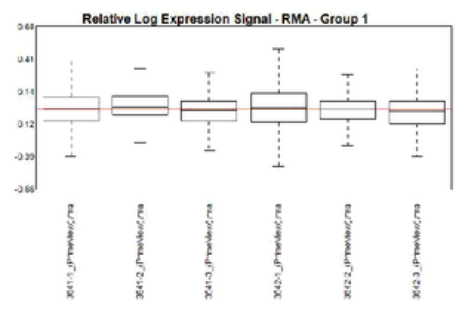

$\mathrm{F}$
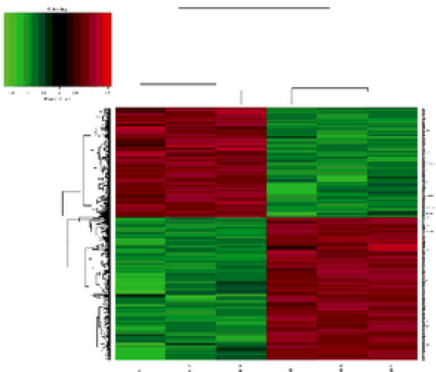

$\mathrm{H}$
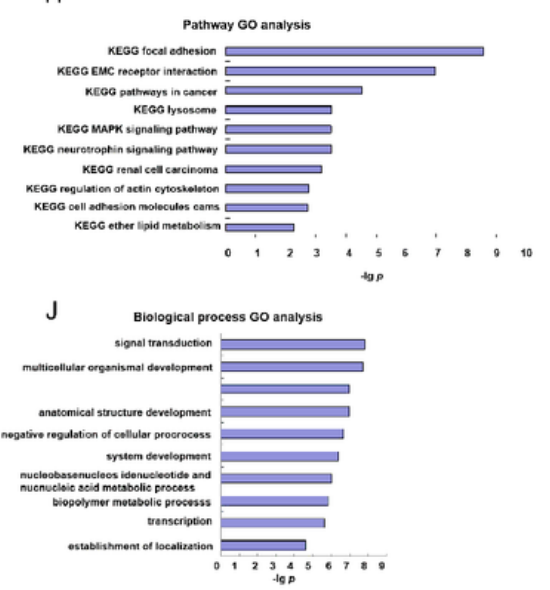

Figure 4

Screening for ATM knockdown-induced TMZ chemotherapy-resistant genes in glioma. A. The RNA in U251NC and U251 siATM cells. B. The Microarray scan in U251 NC and U251siATM cells. C. The signal value distribution of gene chip. D. Relative Log expression signal-RAM-Group 1. E. Pearson's correlation signal-RAM-Group 1. F. The volcano map of gene chip. G. The cluster annalysis of differentially expressed gene of ATM knockdown. $\mathrm{H}$. The pathway analysis of differentially expressed gene of ATM knockdown. I. The molecular function GO analysis of differentially expressed gene of ATM knockdown. J. The biological process $\mathrm{GO}$ analysis of differentially expressed gene of ATM knockdown. K. The cellular component GO analysis of differentially expressed gene of ATM knockdown. 


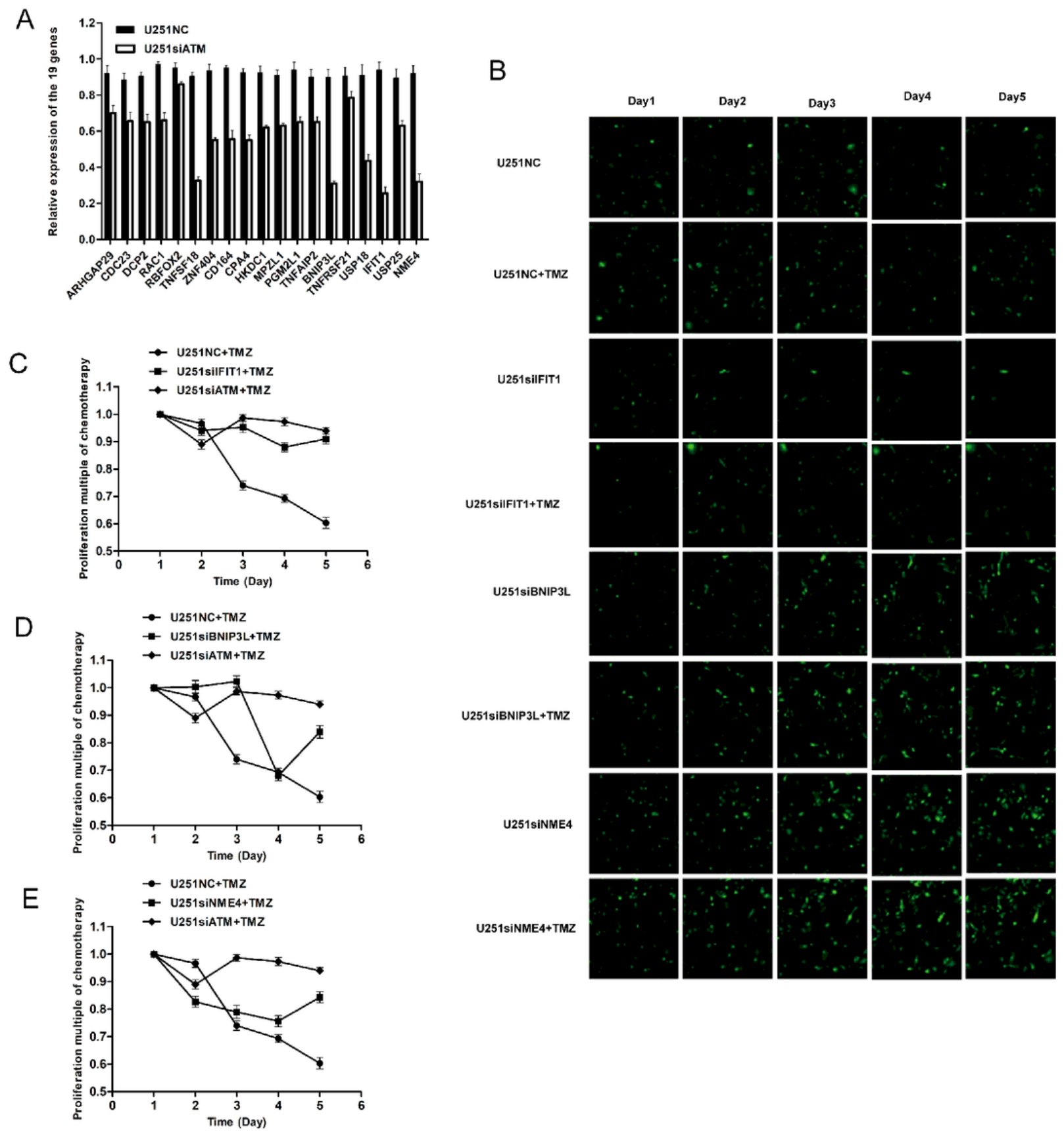

Figure 5

Screening and identification of genes related to ATM knockdown induced TMZ chemotherapy resistance of glioma. A. The relative expressions of 19 candidate genes in U251 cells were detected by qRT-PCR. B. The proliferation of U251 cells at TMZ (IC50) chemotherapy of IFIT1, BNIP3L and NME4 knockdown. C. The proliferation of U251 cells in TMZ (IC50) chemotherapy at IFIT1 knockdown. D. The proliferation of U251 cells in TMZ (IC50) chemotherapy at BNIP3L knockdown. E. The proliferation of U251 cells in TMZ (IC50) chemotherapy at NME4 knockdown. 

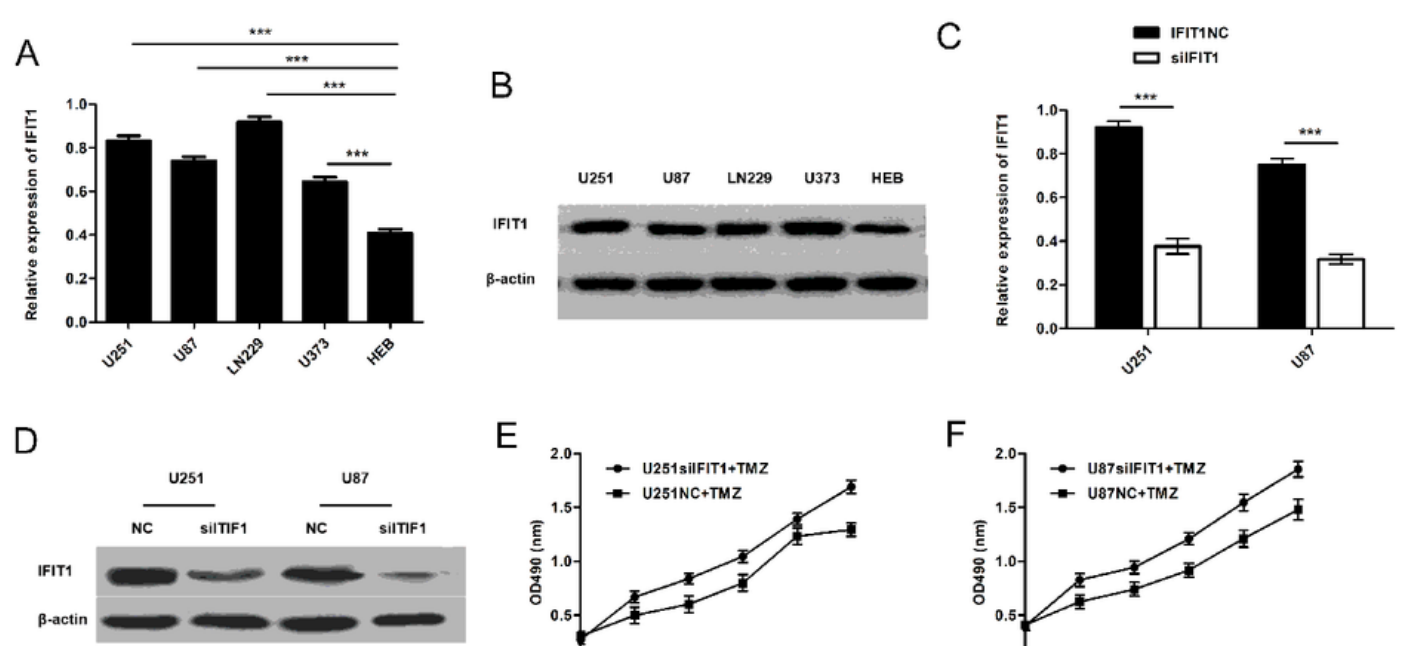

$\mathrm{E}$
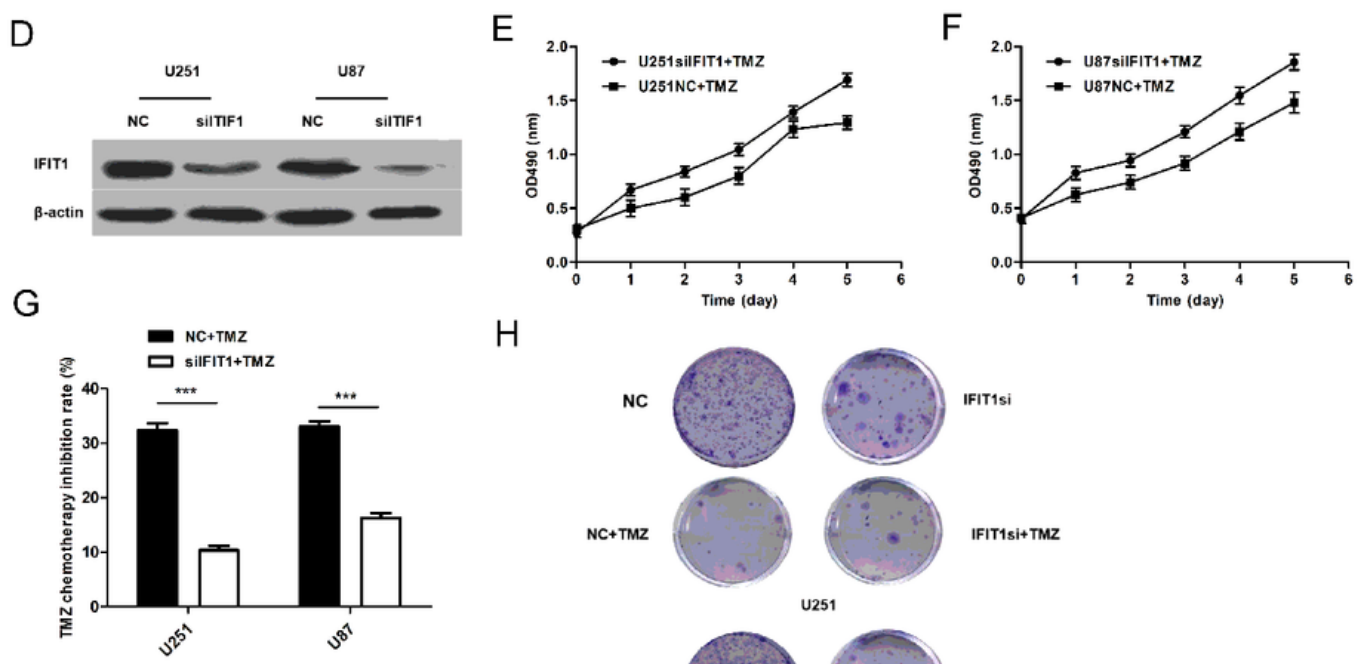

$\mathrm{H}$
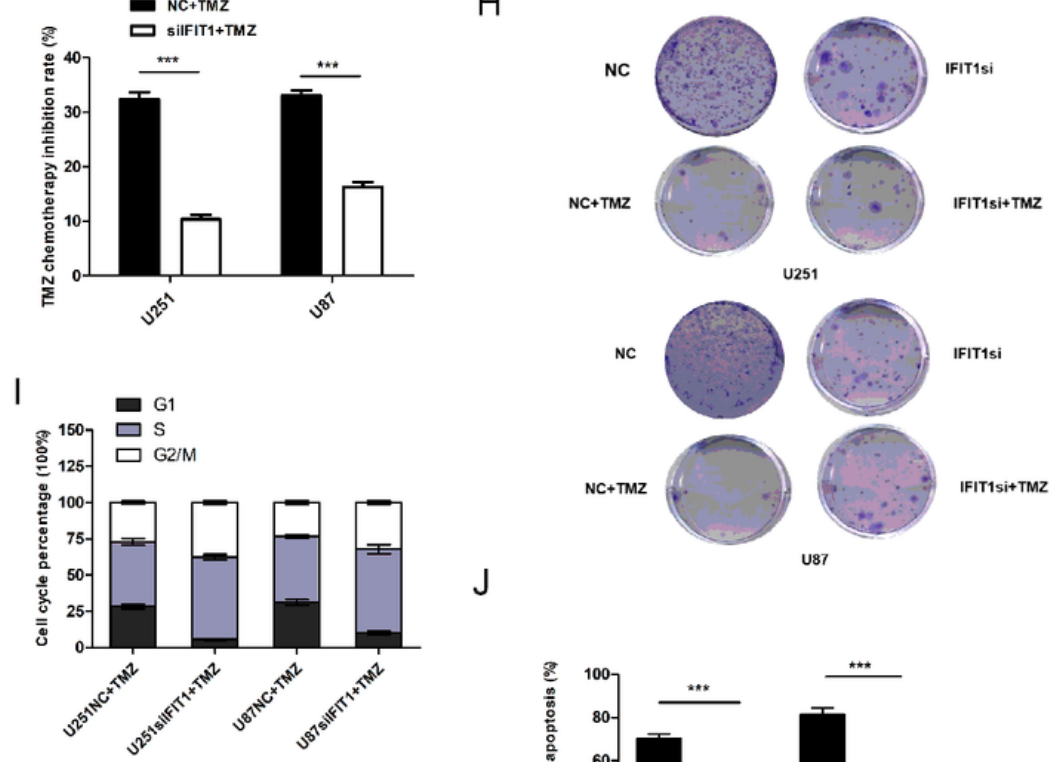

J

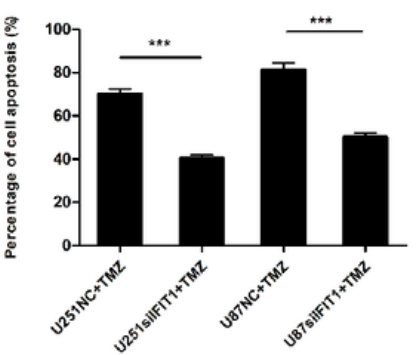

\section{Figure 6}

Role of IFIT1 in glioma cell TMZ chemotherapy. A. qRT-PCR analysis the expression of IFIT1 in U87, U251, LN229, U373 and HEB cell lines. B. Western blot analysis the expression of IFIT1 in U87, U251, LN229, U373 and HEB cell lines. C. qRT-PCR analysis the relative expression of IFIT1 in U251-LV-IFIT1-KD and U87-LV-IFIT1-KD stable cell lines. D. Western blot analysis the relative expression of IFIT1 in U251-LV-IFIT1-KD and U87-LV-IFIT1-KD stable cell lines. E. The proliferation of U251 cells at TMZ (IC50) chemotherapy of IFIT1 knockdown. F. The proliferation of U87 cells at TMZ (IC50) chemotherapy of IFIT1 knockdown. G. The TMZ chemotherapy inhibition rate of U251 and U87 cells when IFIT1 knockdown. H. The clonal formation of U251 and U87 cells at TMZ (IC50) chemotherapy of IFIT1 knockdown. I. The cell cycle percentage of U251 and U87 cells at TMZ (IC50) chemotherapy of IFIT1 knockdown. J. The apoptosis percentage of U251 and U87 cells at TMZ (IC50) chemotherapy of IFIT1 knockdown. ( $\left.{ }^{\star * P}<0.01, \star \star \star P<0.001\right)$. 

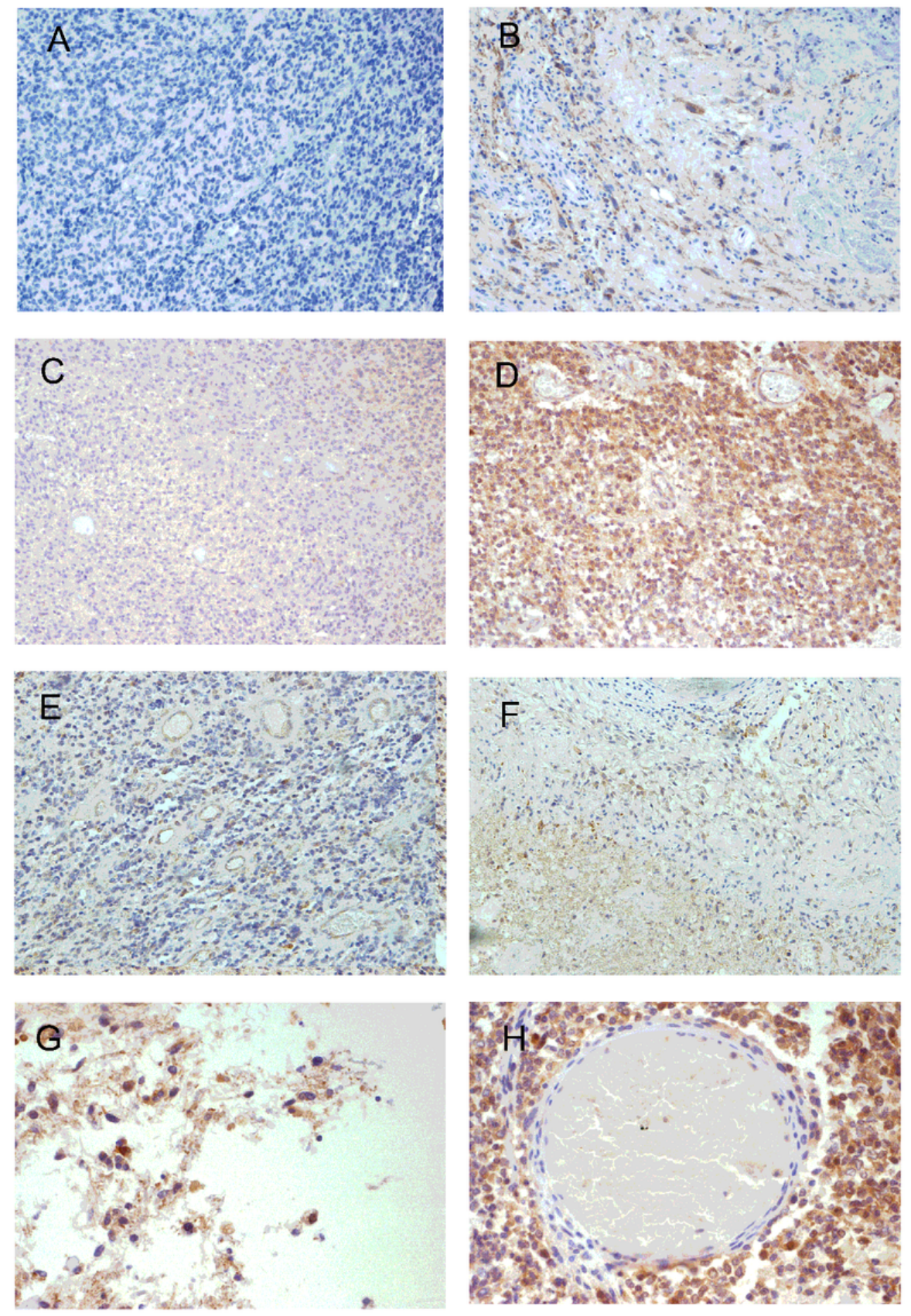

\section{Figure 7}

Immunohistochemical staining was used to evaluate the expression of p-ATM and IFIT1 in glioblastoma tissues. A. Low expression of p-ATM in glioblastoma tissues. B. High expression of p-ATM in glioblastoma tissues. C. Low expression of IFIT1 in glioblastoma tissues. D. High expression of IFIT1 in glioblastoma tissues. E. The expression of IFIT1 in endothelial cells of glioblastoma tissues. F. The expression of IFIT1 in tumor tissue necrosis area of glioblastoma tissues. G. The expression of IFIT1 in edematous area of glioblastoma tissues. H. The expression of IFIT1 in around vascular endothelial cells of glioblastoma tissues. 
A

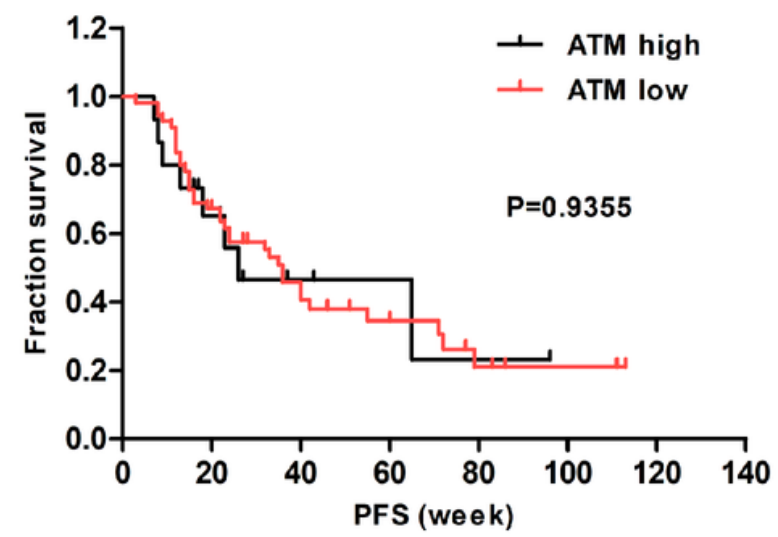

B

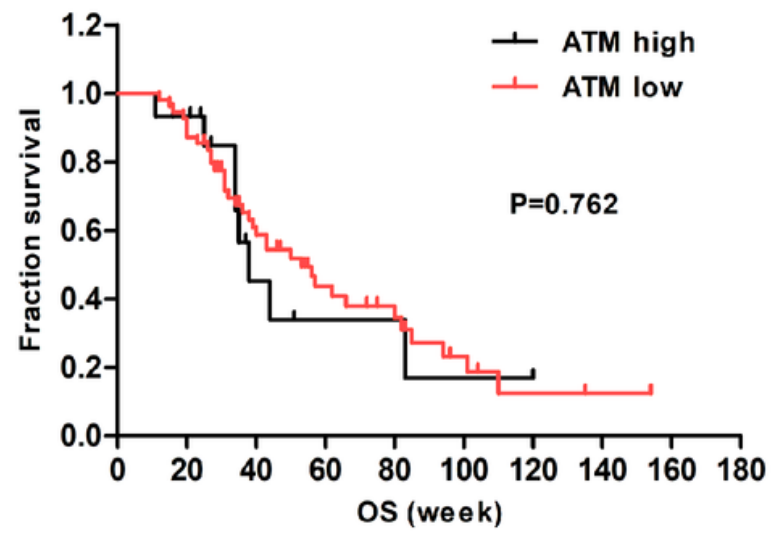

Figure 8

The relationship between the clinical characteristics and expression of p-ATM and IFIT1. A. The relationship between the clinical characteristics and expression of p-ATM. B. The relationship between the clinical characteristics and expression of IFIT1. 